\title{
A review on design, manufacture and mechanics of composite risers
}

\author{
Pham Dinh Chi*, Sridhar Narayanaswamy \\ Engineering Mechanics Department, Institute of High Performance Computing \\ 1 Fusionopolis Way, \#16-16 Connexis, Singapore 138632 \\ Qian Xudong \\ Department of Civil and Environmental Engineering, National University of Singapore \\ 1 Engineering Drive 2, E1A 07-03, Singapore 117576 \\ Adam Sobey, Mithila Achintha and Ajit Shenoi \\ Faculty of Engineering and the Environment, University of Southampton \\ University Road, Southampton, UK, SO17 1BJ
}

\begin{abstract}
Exploration of deeper oceans for oil and gas requires increasingly lightweight solutions. A key enabler in this aspect is the use of fiber-reinforced composite materials to replace metals in risers. However, design synthesis and analyses of composite risers are more challenging than for conventional metals due to the complex behavior and damage mechanisms which composite materials exhibit. Composite risers are predicted to be a high-impact technology that will be mainstream in the medium term but there is still relatively little literature pertaining directly to the behavior of these materials under the complex loading scenarios arising from their use in deep water structures. Therefore there is a need to perform a review and assessment of the available technologies and methodologies in the literature to gain a good understanding of their predictive capabilities, efficiency and drawbacks. This article provides a comprehensive review of published research on manufacture, experimental investigations and numerical analyses of composite risers in deepwater conditions determining the gaps and key challenges for the future to increase their application.
\end{abstract}

Keywords: Composite Riser, Mechanics, Manufacture, oil and gas platforms

*Corresponding author. Tel: +65 64191354; Fax: +65 64674350

Email address: phamdc@ihpc.a-star.edu.sg

\section{Introduction}

Fiber reinforced polymer composites are increasingly being used in the marine and offshore industries. This is especially the case for pipelines/risers, stress joints and fluid handling since composites offer many important advantages over metals due to their high specific strength and stiffness, good durability, low thermal conductivity and good corrosion resistance (Meniconi et al., 2001; Salama et al., 2002; Smith and Leveque, 
2005; Suresh et al., 2004; Tamarelle and Sparks, 1987). The current trend for the offshore industry is towards deeper applications; there were 44 fields over $500 \mathrm{~m}$ depth in 2000 and 200 in 2007 (Quest Offshore, 2011). The production of oil from deep waters is expected to increase from 2.5 million barrels per day in 2004 to 8.25 million barrels in 2015 (Lloyd's Register, 2013).

During this production process the oil must be transported from the well-bore at the seabed to the connecting rig on the surface and this is generally performed through tubes called risers. These risers are long and relatively thin, with predicted depths of $4 \mathrm{~km}$ and typical diameters of $100-300 \mathrm{~mm}$ (Tarnopol'skii et al., 1999). Risers are also used for drilling which transfer mud to the surface or for production which transport hydrocarbons, control fluids or gas. Depending on the operating depth range, different riser configurations are used. Fig. 1 schematically shows different riser/platform configurations together with a range of operating depths. For some riser applications, such as the Tension Leg platform, a problem is that the required top tension escalates considerably with increasing length of the risers.

A number of studies have demonstrated the potential for fiber reinforced polymer (FRP) composites in deep-water risers at water depths more than $1500 \mathrm{~m}$ (Tarnopol'skii et al., 1999), (Beyle et al., 1997). According to Tarnopol'skii et al. (Tarnopol'skii et al., 1999), thermoplastic composite risers (TPCR) offer good solutions to current limited technologies in Top Tensioned Risers (TTRs) and Steel Catenary Risers (SCRs). Both the metal TTRs and SCRs are generally not able to support their own weights at water depths higher than $1500 \mathrm{~m}$ and the costs for these buoyancy and compensation systems may further increase with water depth. Ochoa and Salama (Ochoa and Salama, 2005) acknowledged the potential application of composite risers to extend this capability to a depth of $3000 \mathrm{~m}$ with Tarnopol'skii et al. (Tarnopol'skii et al., 1999) showing a calculation for steel and composite riser design showing that conventional steel risers would be 90,000 tonnes compared to a similar composite riser which would be approximately 20,000 tonnes. Ward et al. (Ward et al., 2007) compared the performance of steel and CFRP composite production risers operating in the Gulf of Mexico. The risers have an approximate length of $1800 \mathrm{~m}$, an outer diameter of $0.3 \mathrm{~m}$ and a wall thickness of $0.25 \mathrm{~m}$. The top tension required for the composite riser was reported by Ward et al. (Ward et al., 2007) 2.7 times less than for the steel using load cases of normal shut-in with 1-year winter storm and 100-year hurricane. Furthermore, the size of the tensioner joint and tapered stress joint needed at the top and bottom of the composite riser system are considerably smaller than the all steel system. Ward et al. (Ward et al., 2007) also reported risk analyses, in terms of the failure modes and hazard, of the steel and composite risers. It was shown that composite risers offer better resistance against many failure modes over steel including burst, collapse, axial yielding of liner, leakage and crack through the liner and the composite tube. However, there are some issues with composites in deep water conditions. Tan et al. (Tan et al., 2015) concluded that composite risers are more vulnerable to vortex-induced-vibrations (VIV) than steel configurations and therefore fatigue damage for the composite yielded $25.5 \%$ higher root mean square (RMS) strains. It is suggested that some of these effects could be negated by increasing the fiber-winding angle increasing the load bearing properties and raising eigenfrequencies, mitigating the VIV. These affects are increased by the degradation of the material properties due to water. Rege and Lakkad (Rege and Lakkad, 1983) showed 
the effects of salt water on glass and carbon fibre materials where the results show that there is a reduction in strength related to the percentage of weight gained, the flexural strength is more severely degraded than other properties. The strength values decrease is related to temperature where an increase leads to greater deterioration, which could be problematic for deeper reservoirs. Siriruk and Penumadu (Siriruk and Penumadu, 2014) studied the effect of sea condition on cyclic fatigue showing that there was a degradation in fatigue, compared to testing of dry laminates in air, of $30 \%$ for wet laminate tested in air which compared to $71 \%$ for dry laminates immersed in water and $84 \%$ for wet laminates immersed in water. This shows a dramatic reduction in the fatigue life of the composite. The results obtained for water confined samples with exposed edges, may overstate the case for marine structures since in many cases only one face will be exposed to sea water and these results show that dry laminated with one side immersed lost $42 \%$ of their cyclic life and wet one side immersed lost 47\%. Kaboudian et al. (Kaboudian et al., 2014) looked at the distribution of tension along a composite riser showing that this was relatively constant and that therefore failures will be more scattered than for steel. They found that the addition of buoys along the riser causes kinks in the tension distribution and advised that long continuous buoys should be added along the bottomhalf of the riser, instead of shorter buoys with gaps. The longer buoys reduce high bending strains at the buoy edges and longer modules are also better at reducing the effects of VIV. Chen et al. (Chen et al., 2013) performed a further study into the effects of VIV in composite risers and showed that the high stiffness of the liner reduces the overall performance of the riser as the high strength of the composite can't be fully utilized. The composite risers require lower top-tension and less or even no buoyancy leads to a significant reduction in the weight hanging from the platform deck, this is economically beneficial which increase with increasing length. Tan et al. (Tan et al., 2015) performed an analysis of coupled fluid-structure simulations against full scale experiments of $1500 \mathrm{~m}$ steel and composite risers. The results show a close correlation and goes on to compare aluminium, steel and titanium liners showing this is the weakest link for composite riser design. The titanium liner riser yielded 20\% lower RMS strains than the aluminum liner riser and 10\% lower RMS stress than the steel liner riser concluding that titanium alloys are a better choice than steel due to their density, wear and corrosion resistance.

Composite risers can be classified into two main types: bonded where there is binding between the riser's layers, and un-bonded where riser's components are able to move relative to each other, shown in Fig. 2. Bonded risers often include a core fiberreinforced angle ply laminate sandwiched between a metallic/elastomeric inner liner and an outer liner made of thermoplastic or thermoset materials or metal alloys where the primary role of the liners is to prevent weeping and leakage of the pressurized media as composite materials are porous (Gibson, 2003). Unbonded flexible risers often comprise an inner steel carcass layer, to prevent buckling and collapse of the riser; steel pressure armor layers, to prevent corrosion from inner fluids; anti-wear homogeneous layers; helically wound tensile armors, to provide axial and bending stiffnesses for the riser, and an outer polymeric layer for external protection (American Petroleum Institute, 2008). One of the first examples of composite risers was for a tension leg platform (Sparks, 1986; Sparks et al., 1998). The risers had an external diameter of about $230 \mathrm{~mm}$, a joint length of $15 \mathrm{~m}$ and were made of hybrid $\pm 20^{\circ}$ carbon and $90^{\circ}$ glass composites and can 
sustain a fatigue life 3 times longer than a steel riser. Other early uses of composites include the development of production (Baldwin et al., 1998; Baldwin et al., 1997) and drilling risers (Andersen et al., 1998a; Andersen et al., 1998b) for deepwater. An example specification of a typical composite riser by $\operatorname{Kim}(\mathrm{Kim}, 2007)$ is presented in Table 1.

The first application of composite risers in the Norwegian North Sea more than 10 years ago (Salama et al., 2002). Salama et al. (Salama et al., 2002) reported a composite riser joint installation in the Heidrun tension leg platform (TLP), which experienced severe loading and operating conditions together with strict regulatory requirements. The qualification program of the Heirdun TLP composite risers included impact, burst pressure and bending fatigue tests on full-scale composite specimens. The composite riser joint was certified by DNV, which participated in the verification and proof testing of the field joint prior to the installation. The offshore field demonstration established a feasible installation process together with an in-service inspection strategy. Despite the high cost of composite risers and riser joints, Salama et al. (Salama et al., 2002) confirmed that composite risers impact the life cycle economics by improving payload capacity, increasing water depth capability, improving overall system safety and reliability, and reducing maintenance costs. In a more recent effort, Miyazaki et al. (Miyazaki et al.) reported the development of a $4000 \mathrm{~m}$ CFRP drilling riser for deep sea drilling vessels. Their research confirmed, via testing of small-scale riser models, the performance of the CFRP risers in the deep-water environment. However, the full implementation of the composite riser requires further enhancement of the connection between the steel flange and the composite pipe, as well as validations of its performance under fatigue and torque loadings. A number of companies have already invested in the development of composite risers around the world, including Conoco, Petrabras, Shell and Statoil. (Gibson, 2003).

Composites demonstrate great potential for deep-sea operations. A recent assessment of industry trends and drivers (Bowden et al., 2014) lists composite risers as a high-impact technology that will be mainstream in the medium term, 2020. However, composites have not been used to their full potential within riser applications. There are examples such as the large safety factors, in the order of 15-50, were recommended by some design standards such as DNV-RP-F202 (Det Norske Veritas, 2009), reflecting the lack of reliable life prediction and lack of rationale and standardization in experiments and modelling. Thus there is a need to advance the understanding on the subject and reduce error and uncertainty margins underpinning safety factors. There has been no recent review of the literature to consolidate this knowledge despite earlier attempts to consolidate an understanding of the behaviour and problems related to composite riser design (Ochoa and Salama, 2005). Therefore the current paper reviews existing work in designing, testing and modelling composite materials at the component and structural levels, summarizes the current state of the art research and identifies key challenges for the future.

\section{Design loads for composite riser}

Summerscales (Summerscales, 2014) described riser environments as "being for long periods of time, often greater than 20 years, with a minimal amount of maintenance under high hydrostatic loads and high thermal gradients". Guesnon et al. (Guesnon et al., 
2002) expanded on these difficulties for ultra-deep water drilling to include water depth, mud weight, auxiliary line diameters and working pressures, sea states and current profiles and maximum rig offset.

The loading scenario is complex as different loads are created by the currents and surface waves, the pressures due to the change in depth and the interaction of the risers with other systems or risers. DNV-OS-F201 (Det Norske Veritas, 2010b) classifies the loads acting on risers under deepwater environments as pressure loads, functional loads, environmental loads and accidental loads, examples of which are given in Table 2. More specifically the design criteria for risers should consider hydrostatic collapse due to buckling load, mechanical collapse under tension, compression, torsion, ovalization, the squashing of the circular risers into an oval shape, and service life factors given in DNVOSS-302 (Det Norske Veritas, 2010a). Each of these loads must be treated differently and there are a number of methods to model each. This review focuses on riser structures and materials aspects but a summary of the environment and loads are included as an integral background to these models.

Risers are subject to pressure loads such as external hydrostatic pressure, internal fluid pressure, both static and dynamic, and the pressure caused by the depth at which the risers operate.

The functional loads include the applied top-tension of risers during the installation or construction, thermal loads due to thermal differences between the sea water and riser structure, or the weight of internal fluid, riser, casings, coatings or buoyancy modules.

Environmental loads are mostly due to the different currents and surface waves. As an example for a riser, Larsen (Larsen, 1992) predicts the currents to be in the region of $1 \mathrm{~m} / \mathrm{s}$ with a wave height of $15 \mathrm{~m}$ and a wave period of $12 \mathrm{~s}$. Some estimated values for the loads and utilization factors of a riser with an internal diameter of $150 \mathrm{~mm}$ at high depth of $\sim 3000 \mathrm{~m}$ are given by Hill et al. (Hill et al., 2006) and reproduced in Table 3. For more details, Patel and Seyed (Patel and Seyed, 1995) provide a review on the modeling and analysis techniques available to make a hydrodynamic assessment of flexible risers giving a good basis for static and dynamic analysis, internal and external pressure effects and includes information on fluid flows.

For many applications, calculations of the hydrodynamic loads typically use Morrison's equation, outlined in (Morison et al., 1950) and (Guesnon et al., 2002). This approach incorporates the drag force due to the relative fluid velocity, the inertia force due to the structural acceleration and the inertia force due to the wave acceleration, albeit that the viscous effects are not accounted for. The fluid velocity and acceleration are specified to estimate fluid drag and inertia loads and the pressure field fluctuation is used to calculate the buoyancy load. However, these equations cannot account for some of the more complex fluid phenomena such as vortex induced vibrations. As the fluid flows pass the body, they can separate creating a pattern of vortices changing the pressure distribution along the body surface. These periodical irregularities of the flow can create vortex induced vibrations with motions in the region of 0.6 diameters ( $\mathrm{He}$ and Low, 2012). These flows are difficult to predict and when the riser is flexible these can result in complex fluid-structure interactions. The longer and more slender the structure is, the more important such interactions become. The vortex-induced vibrations (VIV) are predominant in fatigue of riser structures as investigated by Gao et al. (Gao et al., 2011) 
and the American Bureau of Shipping (ABS) design guide (ABS, 2006) recommends explicit VIV fatigue analysis to mitigate vibration. He and Low (He and Low, 2012) highlighted the importance of vortex-induced vibrations and wake-induced oscillations for predicting the behavior of multiple risers due to clashing. This is an area of much current interest with improvements to the methodologies being presented by many authors including Modarres-Sadeghi et al. (Modarres-Sadeghi et al., 2011) and Dahl et al. (Dahl et al., 2007).

Different from the afore-mentioned loads, accidental loads, such as dropped objects, trawl board impacts or unintended flooding, are defined by a risk analysis and should be assessed with regards to a target failure probability. This ensures that the annual probability of these accidents occurring is less often than a predetermined value, usually in the region of $10^{-3}$ to $10^{-5}$. This is done by estimation of the load effects on the riser design and structure to ensure that the overall failure probability is less than the target failure probability. Standard practices such as DNV-OS-F201 (Det Norske Veritas, $2010 \mathrm{~b}$ ) assume an annual failure probability of $10^{-4}$ for accidental loads on risers with a safety factor of 1 .

Overall, risers are subjected to variable and uncertain loads owing to the harsh environment in which they function. Large wave and current loads can be exacerbated by vortex-induced vibrations and wave-induced oscillations significantly contributing to damage and failure of risers. Structural calculation methods must be capable of dealing with these loading scenarios, and more importantly, the complex interactions that result. Many current analysis methods use simplified loading scenarios to estimate these loads and more complex scenarios must be investigated to see the long terms effects of these additional loads.

\section{Manufacture}

Fiber reinforced polymer composite risers have higher initial material and manufacturing costs than conventional metals but the maintenance costs are lower (Fowler et al., 1998) and there are predictions of a $37 \%$ reduction in overall installation costs (Ochoa and Salama, 2005).

Design and manufacture of composite risers can be mainly considered at the composite riser body, the metal end fittings where multiple risers are joined together and the metal-to-composite interface (MCI). DNV-OSS-302 (Det Norske Veritas, 2010a) provides detailed design criteria for bonded FRP risers in terms of design parameters. The key parameters for bonded risers are the strains of the elastomer layers and the stresses of the reinforcement layers, the liners and the connection mechanisms by the MCI design. The manufacture section of risers can therefore be discussed through two main aspects: the riser body and the MCI and end fittings.

\subsection{Composite riser body}

Composite risers are often manufactured with short segments, called riser joints, fabricated first which are connected together to form a long riser. Composite riser joints are manufactured with a laminated pipe body and metal end fittings with circumferential 
grooves at riser terminations. Pultrusion and filament winding methods are the two main methods to produce FRP composite tubes with constant and tubular cross-sections. The pultrusion method is capable of producing long FRP tubes with small diameters but may not be preferred for fabrication of risers as relatively large diameters are often employed. On the other hand, filament winding is able to make large diameter composite tube though it is restricted to a few-meter length due to the limitation of the mandrel length. This requires that many sections must be joined together to create a suitable length by filament winding. Furthermore, this process is labour intensive increasing the cost and reducing the take up of the material. Nevertheless, wet filament winding is the most popular technique for manufacturing of composite risers (Ochoa, 2006; Pierce, 1987; Salama and Spencer, 2010; Thomas, 2004).

Cocks (Cocks, 1982) patented a method for manufacture of a steel reinforced pipe based on the filament winding. The pipe includes: an inner liner made of wound layers of resin-impregnated glass fibers, a middle structural section made of at least three layers of steel strips of $0.25 \mathrm{~mm}-0.75 \mathrm{~mm}$ thickness and $100 \mathrm{~mm}-200 \mathrm{~mm}$ width which are helically wound about the longitudinal axis of the pipe, axially spaced about $3 \mathrm{~mm}$ and radially spaced smaller than $0.25 \mathrm{~mm}$ from one another; and an outer liner of successive woven glass fiber layers. Such a steel reinforced pipe structure can achieve much higher strength to weight ratio than traditional steel pipes and provide a weight saving of 50 percent of a steel pipe with the same size.

Williams (Williams, 1994) later discovered a composite laminated tubing for marine production risers which is suitable for high temperature change under the sea environment. The pipe comprises multiple FRP composite layers with at least one layer oriented in the longitudinal direction of the pipe and has a low thermal coefficient of expansion and a Poisson ratio from $0.4-0.6$. Such a pipe is highly desirable for use in the environment where small change in pipe's length due to high temperature and pressure variation is expected.

The steps for manufacturing a composite production riser by filament winding were given by Thomas (Thomas, 2004). The first manufacturing step is often to machine the trap-lock MCI which consists of multiple grooves to trap a series of composite layers (Ochoa, 2006; Salama and Spencer, 2010; Thomas, 2004) and installing them on a mandrel. An elastomer layer such as the uncured hydrogen resistant rubber (HNBR) is then wrapped on the mandrel and the MCI to produce an inner liner of the riser. Next, helically wound glass/carbon fibers impregnated with epoxy resin are placed over the HNBR and secured by the trap locking mechanisms of the MCI. Additional circumferential impregnated-fiber layers can be wound to the assembly to provide hoop strengths for the pipe. Subsequently, the mandrel is removed from the assembly and heat is applied to compact all of the layers. After the curing, another layer of HNBR and impregnated fiber may be added and heated again to provide external protection of the assembly against abrasion and external pressure. In this application, the use of HNBR layers allows small relative motions between the metal liner and composite layers; thus helping accommodate for differences in CTE of these layers helping to reduce stress induced microcracks. Recent research efforts (Ramirez and Engelhardt, 2009) have confirmed the performance of the large-scale composite riser tubes under high external pressures. The world's first composite riser installed for the Heidrun platform has used the filament wound technology in the fabrication of the risers (Spencer, 2002). Spencer 
(Spencer, 2002) summarized the manufacturing process, testing and field use of this composite riser project.

For future developments in composite riser manufacture, Salama et al. (Salama and Spencer, 2010) recently invented a method of manufacturing a composite riser section and MCI through filament winding and a horizontal liner assembly, as depicted in Fig. 3. The proposed liner assembly is held in a horizontal position by two supports without inserting a mandrel and rotated about its longitudinal axis by a number of rollers. As described by Salama and Spencer (Salama and Spencer, 2010), composite risers can be constructed with a thin tubular titanium or steel liner which is secured to a connector assembly. Both the metal liner and connector assembly are covered by an elastomer shear ply. A number of helical windings of composite fibers are then placed to form a composite riser section in which at least one winding layer of resin impregnated fibers is oriented at an angle perpendicular to the longitudinal axis of the liner assembly. This composite section is heated to cure the shear ply and composite plies. After this step, external elastomer jackets can be applied and additional composite layers can be wound to secure the jacket and supply external resistance to the composite section. It was claimed that the composite section manufactured with the aforementioned liner assembly will offer excellent strength weight characteristics and durability in comparison with steel risers. Bailey and Miller (Bailey and Miller, 2011) have developed a method to manufacture very long large diameter pipes. This method utilizes a number of pultruded segments which are joined side-by-side rather than end-to-end. Each pultruded segment therefore has a length equal to the length of the desired pipe with as many sections as required for the diameter of the pipe. This reduces the number of joints, and the associated cost while making it easy to transport. Anderson and Altan (Anderson and Altan, 2012) have proposed a method for bladder assisted composite manufacture. This method was reported to be a cost effective method for production of medium to large structural composite components and can be considered as a viable alternative to filament winding, pultrusion, or autoclave curing. The process is similar to flexible bladder molding but the heating source is moved inside the uncured layup. This leads to accurate control of the temperature but also reduces energy requirements by $50 \%$ for cylinders than the traditional bladder approach. Another potential method for composite riser manufacture is pull-winding, a process which is a combination of filament winding and pultrusion. Filament winding is the cheapest method and the easiest to manufacture but can lead to asymmetric layups. Pull braiding is the most expensive process and also the most difficult from manufacturer point of view. Pull-winding is between these two processes providing a compromise between quality and cost (Guz et al., 2015).In the pull winding process, the $0^{\circ}$ oriented material is either fed into the process as a prefabricated rod or fed into the assembly as a pre-preg tape or wet layout. Cross-ply material is then wound onto the tube and the assembly is pulled through a die for integral curing. The pultrusion process may utilize material which is prepared by weaving or braiding the fibers. Woven or braided material can be prepared as feed stock or can be fabricated online as a part of the pultrusion operation (Williams and Sas-Jaworsky, 1999). There were also a number of manufacture methods for spoolable pipes at Deepflex documented in a number of patents: Kalman et al. (Kalman et al., 2013), Chen (Chen, 2014), and Bryant (Bryant, 2006) covering a manufacturing method for an armour layer of a spoolable pipe, a method for flexible pipe structures with a T-shaped cross section and a method of 
securing the inner polymeric core to the first layer of reinforcement for internal fluid pressure resistance. These methods help provide spoolable pipe with increased collapse resistance and enhanced compressive strength.

\subsection{Metal to composite interface and end fitting}

The MCI is mainly used to provide a strong interface/connection between the composite pipe body and the metallic end fittings at pipe's terminations thus may help effectively transfer loads between the pipes. Efficient designs of the MCI are important since their length and mass may significantly affect the weight-effective use of composite risers and failure often occurs at this point during operation.

Roberts and Hatton (Roberts and Hatton, 2013) addressed the importance and design challenges of metallic end fittings at termination of composite pipes. Efficient designs of end fitting are essential to ensure good load transferring between composite and metallic materials as well as to avoid potential failures at the interfaces. Roberts and Hatton (Roberts and Hatton, 2013) presented various arrangement designs for the end fitting of composite risers, as shown in Fig. 4, including the trap-lock end fitting, swaged end fitting, metallic liner end fitting and Magma end fitting. The trap lock end fitting (Fig. 4a) has been the most popular design allowing load transfer between composite and metal components. Another design is the swaged end fitting, shown in Fig. 4b, where metallic inner and outer sleeves are used to sandwich the composite pipe. The inner sleeve fits with the composite bore whilst the outer sleeve is swaged to get an interference fit with the composite pipe. Load transfer is achieved through friction and mechanical interferences. However, there are possibly high stress concentrations and potential damage at the interfaces between the outer sleeve and composite material and at the region where the inner mandrel is inserted. Thus, this design may be suitable only for composite pipes with small diameters. Another design is the metal liner end fitting shown in Fig 4c which is often used in hybrid composite tubes (Cederberg, 2011; Guesnon and Schaeffner, 2002). By this design, the metal liner is directly welded with the end fitting and composite materials are wound over the metal liner. A rubber layer also needs to be applied before winding the composite materials. This design enables the axial load to be handled separately by the metal liner whereas the hoop load is carried by the composite material. It is observed that a long metal liner is required for this configuration reducing the weight saved by using the composite pipes. Recently, Magma has developed another end fitting design, shown in Fig. 4d for a new monolithic structure from bore to surface riser, with high strength carbon fiber and PEEK thermoplastic polymer (Damon, 2011; Magma, 2012; Stephen, 2011). As highlighted by Roberts and Hatton (Roberts and Hatton, 2013), this design allows the thickness at the pipe end to be built up and it is possible to replace of the end fitting, increasing the strength to that of the pipe. Two thickening stages for the composite pipe are suggested to increase the local strength of the pipe at the interface between the pipe and steel outer collar. Sealing between the composite pipe and metal fitting is provided by the use of a preloaded bore seal which can be made of stainless steel or PEEK. It is found that the Magma end fitting design is able to provide good structural interface and increase fatigue performance for both the end fitting and the composite pipe (Roberts and Hatton, 2013). 
While there is a large body of research covering analyses of composite tube under different load applications, studies on the MCI still remain limited. Cederberg (Cederberg, 2011) presented both experimental and numerical analyses of a composite riser joint including the MCI for a pre-stressing step by autofrettage and a factory acceptance test (FAT). Composite and steel components were modelled using a general purpose FE code and their interaction was defined by a surface contact. The FE model of the riser joint is shown in Fig. 5. Tension and pressures following the autofrettage and FAT were applied through five steps: 1) pulling the steel pipe in the axial direction; 2) applying internal pressure at a level greater than its yielding strength; 3) removing the internal pressure; 4) re-applying the pressure at a lower level and 5) releasing the pressure. The stress (ksi) - strain responses of both the steel pipe (X80) and CFRP tube for each step are plotted in Fig. 6. The material responses during the autofrettage and FAT show a high hoop stress and relatively lower axial stress predicted for the composite layers. At the end of the autofrettage step, an interference fit between the steel and composite components is obtained, leaving the composite tube in tension and the pipe in compression. Compressive hoop stress of the steel pipe is shown in Fig. 7. For the composite tube, high fiber stress in each layer is predicted within the constant crosssection region of the composite body and the stress decreases towards the MCI end (Fig. 8).

\subsection{Summary}

Disadvantages on manufacturing techniques such as filament winding or pultrusion form an inhibitor to composite riser construction while keeping the initial production costs relatively high. More difficulties are imposed when there is a lack of infrastructure for mass production of large-diameter and long tubular pipes required for deepwater risers. Filament winding has so far been shown to be one of the most popular fabrication methods for the composite material. Whilst this process has been proven to be beneficial for short-length risers in the future, as manufacture moves towards increased lengths, this might not be the case. This technique will need to be combined with drawing of the tubular shape such as in the pultrusion process though current pultrusion techniques are incapable of the diameters required for offshore applications. A number of new manufacturing processes have emerged such as additive manufacturing providing added benefits in producing long pipes over the current filament winding processes. However, for their introduction surpassing the technical barriers will not be enough. There must be a culture shift to embrace new technologies which will need to be balanced with proof that new techniques ensure a reliable and economic alternative. At the ends of the riser, end fittings with sealing mechanisms are needed to connect different pipe segments to form a long riser. The elastomer liners that are used can easily fail and are therefore not preferred for production and drilling risers. Various types of end fitting designs are discussed in Roberts and Hatton (Roberts and Hatton, 2013) allowing more flexible choices of pipe designs and MCI configurations for the connection between the composite body and metal end fitting. Efficient designs for end fitting are crucial for minimizing the damages at the composite/metal interfaces as well as guarantee good load transferring between the composite pipe and metal components. Apart from these end fitting design, an effective choice of composite material candidates such as the high 
performance Carbon PEEK composite (Damon, 2011; Magma, 2012; Roberts and Hatton, 2013; Stephen, 2011) is also seen to improve the performance of the pipe.

\section{Experimental testing on composite risers}

Over the past decades, numerous experimental programs have been performed to examine the mechanical performance of composite risers under static and fatigue tests to ensure their applicability in the deep-water environment. The testing programs can be grouped into those performed at the material, small-scale structural and full-scale riser levels. While most of the tests are done at the coupon level and some can be found on the small-length risers, existing studies on the large scale risers are still limited.

\subsection{Small-scale material and structural testing}

Ochoa and Ross (Ochoa and Ross, 1998) and Grant and Bradley (Grant and Bradley, 1995) examined the degradation of glass-epoxy and graphite-epoxy composite tubes due to different seawater levels and obtained a good correlation between the analysis and experimental data for flexural response of the composite tubes. Rodriguez and Ochoa (Rodriguez and Ochoa, 2004) reported a four-point bending test comparison between carbon-fiber and glass-fiber epoxy tubes. The composite tube specimens reported have a fixed diameter of $54.8 \mathrm{~mm}$ with a thickness from $2.6 \mathrm{~mm}$ to $3.3 \mathrm{~mm}$. The dominant failure mechanism observed during the test was sub-laminate buckling followed by fracture, located in the axially compressive dies of the composite tube.

Other experimental studies have focused on enhancing the toughness and ductility of the composite riser materials. Sobrinho et al. (Sobrinho et al., 2010; Sobrinho et al., 2011) reported an experimental effort to enhance the toughness of the composite risers by introducing a toughening agent, rubber, into the epoxy resin which increases the elongation of the composite material but results in a compromised tensile strength and a reduced elastic modulus. For riser components and their connections, DNV-RP-F202 (Det Norske Veritas, 2009) suggests test requirements of the MCI on the design phase and after fabrication including axial, bending fatigue tests, stress rupture and external pressure tests of both the MCI and end fittings.

For fatigue, studies on composite tubes include (Soden et al., 1993), (Ellyin et al., 1997), (Ellyin and Martens, 2001), (Mertiny et al., 2004) where the fatigue responses of FRP composite tubes under uniaxial and bi-axial loadings and the effects of fiber orientations on the structural responses were analyzed. Soden et al. (Soden et al., 1993) highlighted the necessity for fatigue testing using tri-axial loads. Ellyin et al. (Ellyin et al., 1997) developed stress-strain curves and biaxial failure envelopes for filament wound specimens. An extension of the study was done by Ellyin and Martens (Ellyin and Martens, 2001) where it is shown that optimum fiber placement in principal directions sometimes lead to weak behavior for intermediate loads and imperfections in the manufacturing process can contribute to damage initiation at the early stage and shorten the fatigue lives of composites. Mertiny et al. (Mertiny et al., 2004) revealed the benefits of the multi-angle winding technology providing more resistance to damage.

With efforts to develop testing methods for full-length composite tubes, Chouchaoui (Chouchaoui and Ochoa, 1999; Chouchaoui et al., 1999) and Rodriguez and 
Ochoa (Rodriguez and Ochoa, 2004) addressed the scaling effects of composite tubes under different loading cases taking into account various geometries, material properties and fiber orientations. However, the developed scaling methods may be applicable to small-scale tubes but have not been fully verified for large-scale specimens.

\subsection{Full-scale riser testing}

Salama et al. (Salama et al., 1998) reported a research program to develop testing and qualification procedures to validate the design and long-term performance of composite production risers for a tension leg platform in the Gulf of Mexico. The testing program developed in their research efforts aims at identifying the performance limitations, failure envelopes and the manufacturing requirements for the composite production risers.

Sparks et al. (Sparks et al., 1998) reported the first mechanical testing of six highperformance composite tubes to be used as production risers for tension-leg-platforms to be used at water depths of 500 to $1000 \mathrm{~m}$ showing that there was an economic benefit in using composite materials for tension-leg-platforms. Salama et al. (Salama et al., 2002) performed mechanical and fatigue tests on full-scale, $15 \mathrm{~m}$ length and $550 \mathrm{~mm}$ diameter, samples demonstrating that composite risers can be designed to satisfy all operational, environmental, and regulatory requirements. Gibson (Gibson, 2003) summarized research on the cost-effective use of FRPs for offshore applications over a 13-year period from 1988 to 2001. This extensive research effort covers a wide spectrum of uses for composite materials in the offshore environment including fire, blast and impact loading and durability.

Recent programs on large scale composite testing have been performed by Ramirez and Engelhardt (Ramirez and Engelhardt, 2009) in which a collapse pressure test was performed on full-scale carbon fiber-epoxy filament-wound tubes of $4.57 \mathrm{~m}$ long, $564 \mathrm{~mm}$ wide and $30.5 \mathrm{~mm}$ thick to determine the capacity of the composite pipes against internal pressure. The study indicates that the delamination in the wall of the composite pipe can cause a significant decrease in the pressure resistance. Other programs on large scale design and manufacturing are reported by Thomas (Thomas, 2004) where drilling and production risers were both assessed statically and for fatigue. 75 short full-scale specimens and 9 MCI joints were tested to empirically characterize strength and fatigue. The program also demonstrated that composite materials would lead to a cost reduction with minimal improvements to the manufacturing process.

\subsection{Summary}

A review of the literature is given in Table 4 which shows that there has been some initial experimental development in investigating the design and mechanical performance of composite risers in deepwater applications. Much of the current analysis has been drawn from experiments on generic composite materials and cylinders. Whilst this allows the general behavior of the materials to be analyzed, specific properties and behavior are still rare. Experimental work mainly focuses on the mechanical behavior of small-scale composite tubes subjected to tension, bending, and burst pressure under different environmental conditions. These developments lead to the subsequent 
development of guidelines on the qualification tests for composite risers in the design codes. However, full-scale tests for the composite pipes are still limited and the significance of scaling effects of risers from small scale to large scale have not been fully addressed in the literature which can reduce the associated manufacture and testing costs required for full-length risers. There is considerably less documented research related to axisymmetric loadings, such as torsion, or related to accidental type loadings, such as burst. This is compounded by the lack of available data related to in-situ behavior of current riser applications making the determination of behavior of composite risers difficult. Through this testing there is little consensus reached on the methods for testing different mechanical or thermo-mechanical conditions that replicate real riser conditions. This will be required to develop accurate testing for components of risers and is a barrier in enabling wider application of composites.

\section{Mechanical behavior modeling}

Current numerical analyses and modeling methods of composite risers originate from the studies on local mechanical behavior of composite tubes under static and fatigue loading and further developed to composite risers considering riser's components and deep water environmental effects. The review on analysis method can be categorized into three main groups covering combined loading, replication of realistic environments and fatigue.

\subsection{Mechanical behavior modeling of composites under combined loading}

There are various studies in literature covering mechanics and nonlinear failure analyses of composite cylinders under complicated load applications which are similar to the conditions that composite risers may undergo under deepwater condition. Most of the studies focus on realistic replication of buckling of composite cylinders under bending and combined loads. Corona and Rodrigues (Corona and Rodrigues, 1995) carried out a study on the bending response of long and thin-walled cross-ply composite cylinders including three phases: pre-buckling response, material failure by Tsai-Wu criterion, and shell-type bifurcation buckling. The bending moment-curvature behavior of the linear elastic composite tube was observed to be nonlinear due to the progressive ovalization of the cross-section, which correlates well with the reports by Brazier (Brazier, 1927) and Reissner and Weinitschke (Reissner and Weinitschke, 1962). Buckling failure can also be considered to occur when maximum compressive stress in the structure reaches the critical stress under pure compression (Seide and Weingarten, 1961) or when the prebuckling load significantly contributes to the bifurcation load through ovalization (Axelrad, 1965, 1987). Higher maximum bucking load of the cylinder is to be attained if the fibers in the inner and outer layers are oriented circumferentially in an analysis without consideration of the nonlinear pre-buckling behavior (Cheng and Ugural, 1968).

For buckling-induced delamination, Theotokoglou (Theotokoglou, 2006) investigated the response of Carbon/PEEK composite tubes with an internal diameter of $177 \mathrm{~mm}$ and thickness of $16 \mathrm{~mm}$ for deepwater applications subjected to external pressure. Although cylinder tubes can fail in multiple ways under combined axial- 
pressure loadings (Marinucci and de Andrade, 2006; Tafreshi, 2004; Wiggenraad et al., 1996), delamination-type failure was commonly encountered in thick composite cylinders (Bai et al., 1997; Rasheed and Tassoulas, 2001; Zhao et al., 2000). Potential delamination of the cylinder can be annular delamination (Kachanov, 1988), strip-type delamination (Timoshenko and Gere, 1961) and buckling of the delamination regions. In (Theotokoglou, 2006), failed elements were removed to reflect the loss of load-carrying capability of the cylinder due to three mode cases: external pressure, thermal loading and buckling load. It is suggested that the delaminated areas may not grow under the design external pressure if no buckling occurs. When buckling is identified, a portion of the delaminated regions cannot carry load and the cylinder will fail at a pressure below the critical design pressure. However, only 2D finite element models were used and 3D finite element models are recommended to verify the results and the effects of length and depth of delamination on the calculation of buckling loads.

\subsection{Mechanical behavior modeling of composite risers under deepwater environment}

Based on numerical methods developed for composite materials, extensions and application of the analysis methods for FRP composite risers requires full consideration of the riser's components, the connection mechanisms and the fluid structure interaction between the structural domain of risers and the sea water domain.

To address the plasticity of liners in composite pipes, Vedvik and Gustafson (Vedvik and Gustafson, 2008) analyzed filament wound thick shells with metal liners subjected to progressive matrix cracking and plastic flow under axial loading. The developed damage models based on the minimum potential energy approach were able to simultaneously predict the progressive transverse cracking of $\left[ \pm 55^{\circ}\right]$ and $\left[ \pm 45^{0}\right]$ laminates and plastic yielding of the metal liner. Mendelson (Mendelson, 1968) employed the successive elastic solution with von Mises yield criterion for plastically modeling the liner. It was found that when both methods were applied in parallel, the equilibrium conditions and two convergence criteria must be fulfilled for every load increment. Andersen (Andersen, 1996) further coupled minimum potential energy approach based on the displacement field with the average maximum stress, average maximum strain, maximum point stress and maximum point strain criteria to effectively model progressive damage.

Recently, Sun et al. (Sun et al., 2013) proposed a homogenization approach for stress analysis of multilayer production risers where composite risers were considered as one homogenized orthotropic layer with blended elastic properties. Stress analyses were performed under typical loading conditions of axial tension, pressure loads, bending and torsion. The stress/strain distribution of the homogenized model follows the orthotropic method presented by Lekhnitskii (Lekhnitskii, 1981), with each layer calculated from those of the homogenized layer through the coefficient matrices. The predicted stress/strain distribution agrees favorably with solutions developed by Xia et al. (Xia et al., 2001) or Tarn and Wang (Tarn and Wang, 2001) who uses a state space approach indicating that extension, torsion and pressuring interact. These deformations are uncoupled with bending of the tube. This method may be accurate for balanced angleply composite laminates but the accuracy must be investigated for composite cylinders 
with unbalanced angle plies. It is also noted that a number of methods can be used for determination of homogenized constants such as those based on constant stress/strain assumption for flat composites by Sun and Li (Sun and Sijian Li, 1988) and Enie and Rizzo (Enie and Rizzo, 1970) or self-consistent mechanics methods for general composites with micro-cracks by Huang et al. (Huang et al., 1993) and Huang and Hu (Huang and $\mathrm{Hu}, 1994$ ).

Additional efforts to account for environmental effects in the global analysis of riser's behavior include Meniconi et al. (Meniconi et al., 2001) who used hydrodynamic finite element methods to estimate the axial forces and bending moments of the hybrid carbon and glass epoxy composite risers for a tension leg platform considering different environmental loads. Progressive failure analyses of composite taper joints were also carried out and stresses at various sections of the joint were evaluated based on the thick cylinder theory. The maximum stress criterion and progressive failure approach proposed in Hinton et al. (Hinton et al., 1996) was adopted for delamination analysis of the taper joints, an initial crack was assumed and a virtual crack closure technique was applied. The results show that composite risers which satisfy design and strength requirements can weigh half as much as an equivalent steel riser. In addition, Pina et al. (Pina et al., 2011) and Vieira et al. (Vieira et al., 2008) utilized an analytical catenary solver to perform a global analysis of bonded composite risers. Abouhamze and Shakeri (Abouhamze and Shakeri, 2007), Larson and Hanson (Larsen and Hanson, 1999) and Lima et al. (Leite Pires de Lima et al., 2005) carried out static finite analyses to estimate the axial force of the risers and account for the inextensibility conditions of the riser under distributed vertical load. Ramos and Pesce (Ramos and Pesce, 2004) presented an analytical model to predict the behavior of flexible risers under complex combination of loads including bending, twisting, tension with the presence of internal and external pressure. The successful modeling of stick-slip behaviors between the riser layers allows a coupling between bending and axisymmetric loads. Whilst advocating the benefits of optimization techniques for composite risers, due to their complexity, Silva et al. (Silva et al., 2013) showed a global-local method which was used instead of shell models, which have a prohibitively high computational cost for full riser structures. The model was based on a simplified catenary solver for the global model and classical laminate plate theory for the local model. Though it is proposed as a robust implementation environmental loads and fatigue were ignored making it unsuitable for detailed studies. Recently, Pham et al. (Pham et al., 2014) and Edmans et al. (Edmans et al., 2014) have described a sequential local-global approach for multiscale modeling of unbonded flexible risers subjected to combined loadings. RVE analyses of flexible pipes were first performed to derive nonlinear constitutive model for flexible risers based on homogenization theory and the analogy between slipping mechanisms observed in flexible pipe and the elasto-plastic behavior of materials. Global analysis or risers were then performed using hybrid beam elements and the developed constitutive model to effectively predict the response of the risers under axial loading, bending, torsion and internal and external pressures. Sun et al. (Sun et al., 2014) propose another homogenization method for anisotropic composite cylindrical structures comparing the results to two different FEA methods, one based on multiple solid elements through the thickness and the second where the liner, the outer layer, the 20 composite layers are modeled with one through-thickness element each. The results demonstrate excellent correlation across a number of different loading conditions, 
axial force, internal and external pressure, axial and in-plane shear, bending moments and torsion whilst also showing that both FEM methods provide similar results. The examples showed that the material anisotropy may have significant effects on the effective axial, torsional and coupling stiffness coefficients of composite cylindrical structures but insignificant effects on the effective bending stiffness coefficient.

A key part of the riser analysis is the linkage between the global and local models. Chen et al. (Chen et al., 2013) use the critical moments, pressures and tensions obtained from a global analysis to check the local structural strength which provides a simple and effective method of linking the global and local analysis. A similar method is utilized by Silva et al. (Silva et al., 2013) using load and amplification factors to account for pressure, bending moments and environmental loads through the tension forces of classical laminate plate theory. Pham et al. (Pham et al., 2015) described a nested multiscale method for flexible risers to concurrently link the global analysis of the flexible pipe and the RVE analysis of the local regions of interests in every load step. A linking procedure between the scales has been implemented through Python scripting and restart analyses.

\subsection{Fatigue analysis}

Fatigue of composites may start from the microscopic scale which involves microscopic failure in constituent fiber, matrix or fiber/matrix interface to the macroscopic scale that considers failure at structural level. Fatigue of composites significantly differs from metals since stiffness degradation can be observed early during the initial stages of fatigue and may potentially lead to major stiffness reduction during the fatigue process.

Determination of the fatigue behavior of composites at the material level is driven primarily by other industries and specific investigations into the fatigue performance of a FRP riser product remains scant. As highlighted by Ochoa and Salama (Ochoa and Salama, 2005), the lack of experimental database for long-term damage mechanisms required by the accurate fatigue life prediction remains as one of the basic technical barriers for wide industrial applications of composite risers. A reliable S-N curve has not yet evolved for composite risers. The lack of experimental efforts on the composite risers leads to a large factor of safety (15 to 50) in the offshore design recommendations (Det Norske Veritas, 2009). The fatigue failure of a composite riser product is evidently a complex process, involving multiple failure mechanisms. Huybrechts (Huybrechts, 2002) highlighted that the design of the CFRP composite riser should ensure that the fatigue failure is determined predominantly by the fiber-failure to ensure a long lifetime of the riser. The fatigue design procedure outlined in the design guideline thus follows primarily the approach developed for wind turbine blades (Echtermeyer et al., 1996), of which the fatigue failure mechanism remains mainly the fiber failure. The high uncertainties in the DNV guidelines, as reflected by the large factors of safety, derive essentially from the Miner's rule, which does not provide a satisfactory description of the fatigue performance of composite materials, as demonstrated by experimental investigations (Broutman and Sahu, 1972). The development of a comprehensive fatigue design procedure requires extensive experimental data for composite riser prototypes fabricated following the exact procedure as that for commercial products. Some research, led by industrial companies 
(Cederberg, 2011; Huybrechts, 2002), have started fatigue tests on composite riser specimens. However, no detailed results are available in public literature.

\subsection{Summary}

Overall, research on composite pipes over the last few decades has covered the buckling responses and possible delamination-type failures in composites due to bending, compression or combined axial-bending loadings which can be representative of complicated loading conditions that composite risers are subject to. Table 5 highlights numerical methods for composite risers and it is possible to see that the modelling is often performed at a simple and analytical level. As highlighted the environmental conditions for risers lead to a complex interaction of loads but there are limited investigations into composite risers under realistic deepwater conditions fully considering the interaction effects between different mechanical and environmental loads. Further developments on effective numerical models of composite risers subject to mimicked deepwater environment are crucial. It is suggested that efficient multiscale approaches with consistent scale bridging methods may be used to allow for prediction of both global response of risers under realistic deep sea environment and local responses of riser structures and their components. It has also been shown that long-term fatigue database for composite risers are not fully available in the literature. Finally, an important element in the determination of safety is stochastic approaches and Thomas (Thomas, 2004) has shown the benefits of a reliability based approach for risers. A review of the literature pertaining to the generation of safety factors for composite risers shows no freely available studies have been performed. Studies into the reliability of composite risers in deepwater will provide an important step in increasing the safety associated with riser design.

\section{Conclusion}

With the growing importance of deep-water exploitation there is an increasing benefit in deploying composite risers. There is currently no state of the art review focusing on the design, manufacture and associated mechanics of composite materials in risers, this article aims to provide such a review. The most notable barriers that hinder the application of composite risers to its full potential are (i) manufacturing techniques and infrastructure to cost-effectively produce long tubular composite structures (ii) a lack of full-scale and in-situ results for verification and certification, thus resulting in a requirement for material properties to assess long term damage and (iii) modelling that takes into account the interaction of the wide range of loads that risers see in-situ and stochastic analysis techniques to help reduce the large safety factors in the currently available design standards. The review shows that the predicted benefits of using composite materials for risers are large with potential weight savings, decreased costs and increased structural strengths. Reviews on experimental studies signify the importance of multiscale level testing of composite risers including the scaling effects to bring the research testing close to practical applications. In addition, effective numerical approaches accounting for fluid-structure interaction are essential for better predicting the 
response of composite risers under harsh deep sea environment. Reliability and fatigue studies of composite risers are limited, it is recommended that further research in these fields are crucial to ensure expanded utilization of composite risers in deepwater applications.

\section{Acknowledgment}

Funding support for this work from the Science and Engineering Research Council (SERC) of the Agency of Science, Technology and Research (A*STAR), Singapore is gratefully acknowledged.

\section{References}

Abouhamze, M., Shakeri, M., 2007. Multi-objective stacking sequence optimization of laminated cylindrical panels using a genetic algorithm and neural networks. Composite Structures 81 (2), 253-263.

ABS, 2006. Guide for building and classing subsea riser systems.

American Petroleum Institute, 2008. Specification for Unbonded Flexible Pipe, ANSI/API Specification 17J/ ISO 13628-2.

Andersen, R., 1996. Analysis of transverse cracking in composite structures. PhD Thesis, Norwegian Institute of Technology of Science, Trondheim, Norway, ISBN 82-7119-9080, ISSN 0802-3271.

Andersen, W.F., Anderson, J.J., Landriault, L.S., 1998a. Full-Scale Testing of Prototype Composite Drilling Riser Joints-Interim Report. Offshore Technology Conference.

Andersen, W.F., Burgdorf, O., Jr., Sweeney, T.F., 1998b. Comparative Analysis of 12,500 ft. Water Depth Steel and Advanced Composite Drilling Risers. Offshore Technology Conference.

Anderson, J.P., Altan, M.C., 2012. Properties of Composite Cylinders Fabricated by Bladder Assisted Composite Manufacturing. Journal of Engineering Materials and Technology 134 (4), 044501-044501.

Axelrad, E.L., 1965. Refinement of critical load analysis for tube flexure by way of considering precritical deformation. Izvestiia AN SSSR OTN, Mekhanikai, Mashinostroenie, 123-129.

Axelrad, E.L., 1987. Theory of Flexible Shells, North-Holland, Amsterdam.

Bai, J., Seeleuthner, P., Bompard, P., 1997. Mechanical behaviour of $\pm 55^{\circ}$ filamentwound glass-fibre/epoxy-resin tubes: I. Microstructural analyses, mechanical behaviour and damage mechanisms of composite tubes under pure tensile loading, pure internal pressure, and combined loading. Composites Science and Technology 57 (2), 141-153. 
Bailey, S.L., Miller, A.K., 2011. Pultruded Arc-Segmented Pipe. Google Patents.

Baldwin, D.D., Lo, K.H., Long, J.R., 1998. Design Verification of a Composite Production Riser. Offshore Technology Conference.

Baldwin, D.D., Newhouse, N.L., Lo, K.H., Burden, R.C., 1997. Composite Production Riser Design. Offshore Technology Conference.

Beyle, A.I., Gustafson, C.G., Kulakov, V.L., Tarnopol'skii, Y.M., 1997. Composite risers for deep-water offshore technology: Problems and prospects. 1. Metal-composite riser. Mechanics of Composite Materials 33 (5), 403-414.

Bowden, J., Bovingdon, T., Dalton, J., Gavin, J., Kielstra, P., McCauley, D., Solloway, S., Watson, J., 2014. The Lloyd's Register Energy Oil And Gas Technology Radar 2014 An assessment of the sector's innovation trends and drivers. Lloyd's Register Energy Report.

Brazier, L.G., 1927. On the Flexure of Thin Cylindrical Shells and Other "Thin" Sections. Proceedings of the Royal Society of London. Series A 116 (773), 104-114.

Broutman, L.J., Sahu, S., 1972. A new theory to predict cumulative fatigue damage in GRP, Composite Materials: Testing and Design. 2nd ASTM STP 497, 170-188.

Bryant, M.J., 2006. Anti-collapse system and method of manufacture. Google Patents.

Cederberg, C., 2011. Design and Verification Testing Composite-Reinforced Steel Drilling Riser, Final Report, RPSEA 07121-1401. Lincoln Composites, Inc.

Chen, B., 2014. Composite flexible pipe and method of manufacture. Google Patents.

Chen, Y., Tan, L.B., Jaiman, R.K., Sun, X., Tay, T.E., Tan, V.B.C., 2013. Global-Local Analysis of a Full-Scale Composite Riser During Vortex-Induced Vibration, ASME 2013 32nd International Conference on Ocean, Offshore and Arctic Engineering, OMAE201311632. ASME.

Cheng, S., Ugural, A.C., 1968. Buckling of composite cylindrical shells under pure bending. AIAA Journal 6 (2), 349-354.

Chouchaoui, C.S., Ochoa, O.O., 1999. Similitude study for a laminated cylindrical tube under tensile, torsion, bending, internal and external pressure. Part I: governing equations. Composite Structures 44 (4), 221-229.

Chouchaoui, C.S., Parks, P., Ochoa, O.O., 1999. Similitude study for a laminated cylindrical tube under tension, torsion, bending, internal and external pressure Part II: scale models. Composite Structures 44 (4), 231-236.

Cocks, P.J., 1982. Steel reinforced pipe. Google Patents. 
Corona, E., Rodrigues, A., 1995. Bending of long cross-ply composite circular cylinders. Composites Engineering 5 (2), 163-182.

Dahl, J.M., Hover, F.S., Triantafyllou, M.S., Dong, S., Karniadakis, G.E., 2007. Resonant Vibrations of Bluff Bodies Cause Multivortex Shedding and High Frequency Forces. Physical Review Letters 99 (14), 144503.

Damon, R., 2011. Carbon/polymer pipes for critical jumper spool applications, ASME IOPF.

Det Norske Veritas, 2009. Recommended Practice for Composite Risers DNV-RP-F202

Det Norske Veritas, 2010a. Offshore riser system, Offshore service specification DNVOSS-302

Det Norske Veritas, 2010b. Recommended Practice for Dynamic Risers, DNV-OS-F201

Echtermeyer, A.T., Kensche, C., Bach, P., Poppen, M., Lilholt, H., Andersen, S.I., Brøndsted, P., 1996. Method to predict fatigue lifetimes of GRP wind turbines blades and comparison with experiments, in: Helm, P. (Ed.), 1996 European Union wind energy conference. Proceedings. H.S. Stephens \& Associates, Bedford, pp. 907-913.

Edmans, B., Pham, D.C., Guo, T.F., Zhang, Z., Narayanaswamy, S., Stewart, G., 2014. Multiscale Finite Element Analysis of Unbonded Flexible Risers, ASME 2014 33rd International Conference on Ocean, Offshore and Arctic Engineering. Volume 6B: Pipeline and Riser Technology, San Francisco, California, USA.

Ellyin, F., Carroll, M., Kujawski, D., Chiu, A.S., 1997. The behavior of multidirectional filament wound fibreglass/epoxy tubulars under biaxial loading. Composites Part A: Applied Science and Manufacturing 28 (9-10), 781-790.

Ellyin, F., Martens, M., 2001. Biaxial fatigue behaviour of a multidirectional filamentwound glass-fiber/epoxy pipe. Composites Science and Technology 61 (4), 491-502.

Enie, R.B., Rizzo, R.R., 1970. Three-Dimensional Laminate Moduli. Journal of Composite Materials 4 (1), 150-154.

Fowler, H., Feechan, M., Berning, S., 1998. Development update and applications of an advanced composite spoolable tubing, Offshore Technology Conference, , Houston, Texas.

Gao, Y., Zong, Z., Sun, L., 2011. Numerical prediction of fatigue damage in steel catenary riser due to vortex-induced vibration. Journal of Hydrodynamics, Ser. B 23 (2), 154-163.

Gibson, A.G., 2003. The cost effective use of fiber reinforced composites offshore. Research Report for the Health and Safety Executive, University of Newcastle Upon Tyne. 
Grant, T.S., Bradley, W.L., 1995. In-Situ Observations in SEM of Degradation of Graphite/Epoxy Composite Materials due to Seawater Immersion. Journal of Composite Materials 29 (7), 852-867.

Guesnon, J., Gaillard, C., Richard, F., 2002. Ultra Deep Water Drilling Riser Design and Relative Technology. Oil and Gas Science and Technology 57 (1), 39-57.

Guesnon, J., Schaeffner, P., 2002. Hybrid Tubes for Choke and Kill Lines. Offshore Technology Conference.

Guz, I.A., Menshykova, M., Paik, J.K., 2015. Thick-walled composite tubes for offshore applications: an example of stress and failure analysis for filament-wound multi-layered pipes. Ships and Offshore Structures, 1-19.

He, J.W., Low, Y.M., 2012. An approach for estimating the probability of collision between marine risers. Applied Ocean Research 35 (0), 68-76.

Hill, T., Zhang, Y., Kolanski, T., 2006. The future for flexible pipe riser technology in deep water: case study, Offshore Technology Conference, , Houston, Texas.

Hinton, M.J., Soden, P.D., Kaddour, A.S., 1996. Strength of composite laminates under biaxial loads. Applied Composite Materials 3 (3), 151-162.

Huang, C., 2012. Structural Health Monitoring System for Deepwater Risers with Vortex-induced Vibration: Nonlinear Modeling, Blind Identification Fatigue/Damage Estimation and Local Monitoring using Magnetic Flux Leakage, PhD final report of RPSEA project, 07121-DW1603D, Rice University.

Huang, Y., Hu, K.X., 1994. Elastic moduli of a microcracked composite with spherical inclusions of cubic anisotropy. Composites Science and Technology 50 (2), 149-156.

Huang, Y., Hu, K.X., Chandra, A., 1993. The effective elastic moduli of microcracked composite materials. International Journal of Solids and Structures 30 (14), 1907-1918.

Huybrechts, D.G., 2002. Composite Riser Lifetime Prediction. Offshore Technology Conference.

Kaboudian, A., Tan, L.B., Jaiman, R.K., Chen, Y., Tan, V.B.C., 2014. Semi-Empirical VIV Analysis of Full-Scale Deepwater Composite Risers, ASME 2014 33rd International Conference on Ocean, Offshore and Arctic Engineering, OMAE2014-23529., San Francisco, California, USA.

Kachanov, L., 1988. Delamination Buckling of Composite Materials. Kluwer Academic Publishers, Boston.

Kalman, M.D., Yu, L., Moosberg, D.G., McCall, D.M., Seymour, M.A., 2013. Spoolable pipe with increased compressive strength and method of manufacture. Google Patents. 
Kim, W.K., 2007. Composite production riser assessment. PhD dissertation, Texas A\&M University.

Larsen, C.M., 1992. Flexible riser analysis - comparison of results from computer programs. Marine Structures 5 (2-3), 103-119.

Larsen, C.M., Hanson, T., 1999. Optimization of Catenary Risers. Journal of Offshore Mechanics and Arctic Engineering 121 (2), 90-94.

Leite Pires de Lima, B.d.S., Pinheiro Jacob, B., Francisco Favilla Ebecken, N., 2005. A hybrid fuzzy/genetic algorithm for the design of offshore oil production risers. International Journal for Numerical Methods in Engineering 64 (11), 1459-1482.

Lekhnitskii, S.G., 1981. Theory of Elasticity of an Anisotropic Body. Mir Publishers, Moscow.

Lindsey, C.G., Masudi, H., 1999. Tensile fatigue testing of composite tubes in seawater, ASME Energy Sources Technology Conference, , Houston, Texas.

Lloyd's Register, 2013. Global Marine Trends 2030 Lloyd's Register's Strategic Research Group, QinetiQ and The University of Strathclyde.

Magma, G., 2012. Carbon fiber pipe for risers, SUT conference, London.

Marinucci, G., de Andrade, A.H.P., 2006. Microstructural analysis in asymmetric and unbalanced composite cylinders damaged by internal pressure. Composite Structures 72 (1), 86-90.

Mendelson, A., 1968. Plasticity: theory and applications, New York: MacMillan.

Meniconi, L.C.M., Reid, S.R., Soden, P.D., 2001. Preliminary design of composite riser stress joints. Composites Part A: Applied Science and Manufacturing 32 (5), 597-605.

Mertiny, P., Ellyin, F., Hothan, A., 2004. An experimental investigation on the effect of multi-angle filament winding on the strength of tubular composite structures. Composites Science and Technology 64 (1), 1-9.

Miyazaki, E., Kyo, M., Seki, H., Takasaki, H., Development of 4,000 m Class CFRP Drilling Riser. Offshore Technology Conference.

Modarres-Sadeghi, Y., Chasparis, F., Triantafyllou, M.S., Tognarelli, M., Beynet, P., 2011. Chaotic response is a generic feature of vortex-induced vibrations of flexible riser. Journal of Sound and Vibration 330 (11), 2565-2579.

Morison, J.R., Johnson, J.W., Schaaf, S.A., 1950. The Force Exerted by Surface Waves on Piles. 2 (5), 149 - 154. 
Ochoa, O.O., 2006. Composite riser experience and design guidance, Final Project Report prepared for the Minerals Management Service under the MMS/OTRC Cooperative Research Agreement 1435-01-04-CA-35515, Task Order 35985, MMS Project Number 490, , Texas A\&M University.

Ochoa, O.O., Ross, G.R., 1998. Hybrid Composites: Models and Tests for Environmental Aging. Journal of Reinforced Plastics and Composites 17 (9), 787-799.

Ochoa, O.O., Salama, M.M., 2005. Offshore composites: Transition barriers to an enabling technology. Composites Science and Technology 65 (15-16), 2588-2596.

Oil \& Gas Journal, 1998. Flexible market expanding as facility pushes out technical limits. http://www.offshore-mag.com 58 (10).

Patel, M.H., Seyed, F.B., 1995. Review of flexible riser modelling and analysis techniques. Engineering Structures 17 (4), 293-304.

Pham, D.C., Guo, T.F., Zhang, Z., Narayanaswamy, S., Edmans, B., 2014. An Effective Constitutive Model for Unbonded Flexible Risers. Offshore Technology Conference.

Pham, D.C., Zhang, Z., Guo, T., Narayanaswamy, S., Edmans, B., Stewart, G., 2015. Multiscale modeling approach for flexible risers, 20th International Conference on Composite Materials. ICCM, Copenhagen.

Pierce, R.H., 1987. Composite Marine Riser System, Patent US4634314 A.

Pina, A., Albrecht, C., Lima, B., Jacob, B., 2011. Tailoring the particle swarm optimization algorithm for the design of offshore oil production risers. Optimization and Engineering 12 (1-2), 215-235.

Quest Offshore, 2011. The state of the offshore US oil and gas industry, Prepared for the American Petroleum Institute, Texas, USA

Ramirez, G., Engelhardt, M.D., 2009. Experimental Investigation of a Large-Scale Composite Riser Tube Under External Pressure. Journal of Pressure Vessel Technology 131 (5), 051205-051205.

Ramos, J.R., Pesce, C.P., 2004. A Consistent Analytical Model to Predict the Structural Behavior of Flexible Risers Subjected to Combined Loads. Journal of Offshore Mechanics and Arctic Engineering 126 (2), 141-146.

Rasheed, H., Tassoulas, J., 2001. Delamination growth in long composite tubes under external pressure. International Journal of Fracture 108 (1), 1-23.

Rege, S.K., Lakkad, S.C., 1983. Effect of salt water on mechanical properties of fibre reinforced plastics. Fibre Science and Technology 19 (4), 317-324. 
Reissner, E., Weinitschke, H.J., 1962. Finite Pure Bending of Circular Cylindrical Tubes. Defense Technical Information Center, MIT Cambridge.

Roberts, D., Hatton, S.A., 2013. Development and Qualification of End Fittings for Composite Riser Pipe. Offshore Technology Conference.

Rodriguez, D.E., Ochoa, O.O., 2004. Flexural response of spoolable composite tubulars: an integrated experimental and computational assessment. Composites Science and Technology 64 (13-14), 2075-2088.

Salama, M.M., Johnson, D.B., Long, J.R., 1998. Composite Production Riser Testing and Qualification. Society of Petroleum Engineers 13 (3), 170-177.

Salama, M.M., Spencer, B.E., 2010. Method of manufacturing composite riser. Google Patents.

Salama, M.M., Stjern, G., Storhaug, T., Spencer, B., Echtermeyer, A., 2002. The first offshore field installation for a composite riser joint, Offshore technology conference, , Houston, TX.

Seide, P., Weingarten, V.I., 1961. On the Buckling of Circular Cylindrical Shells Under Pure Bending. Journal of Applied Mechanics 28 (1), 112-116.

Silva, R.F.d., Teófilo, F.A.F., Parente Jr, E., Melo, A.M.C.d., Holanda, A.S.d., 2013. Optimization of composite catenary risers. Marine Structures 33 (0), 1-20.

Siriruk, A., Penumadu, D., 2014. Degradation in fatigue behavior of carbon fiber-vinyl ester based composites due to sea environment. Composites Part B: Engineering 61, 9498.

Smith, K.L., Leveque, M.E., 2005. Ultra-deepwater production systems, Final report, Houston, TX.

Sobrinho, L.L., Calado, V.M.d.A., and Bastian, F.L., 2010. Development of composite pipes for riser application in deep water. American Society of Mechanical Engineers, Pressure Vessels and Piping Division 6, 293-301.

Sobrinho, L.L., Calado, V.M.d.A., Bastian, F.L., 2011. Development and characterization of composite materials for production of composite risers by filament winding. Materials Research 14, 287-298.

Soden, P.D., Kitching, R., Tse, P.C., Tsavalas, Y., Hinton, M.J., 1993. Influence of winding angle on the strength and deformation of filament-wound composite tubes subjected to uniaxial and biaxial loads. Composites Science and Technology 46 (4), 363378. 
Sparks, C., 1986. Lightweight composite production risers for a deepwater tension leg platform, 5th International Conference on Offshore Mechanics and Arctic Engineering, Tokyo, Japan, pp. 86-93.

Sparks, C.P., Odru, P., Bono, H., Metivaud, G., 1998. Mechanical Testing Of HighPerformance Composite Tubes For Tlp Production Risers. Offshore Technology Conference, Houston, Texas.

Spencer, B.E., 2002. Composite solutions for high pressure drilling risers, 47th International Sampe symposium and exhibitiion, California, USA, pp. 703-715.

Stephen, H., 2011. Composite pipe for FPSO risers, FPS 2011 conference.

Summerscales, J., 2014. Durability of Composites in the Marine Environment, in: Davies, P., Rajapakse, Y.D.S. (Eds.), Durability of Composites in a Marine Environment. Springer Netherlands, pp. 1-13.

Sun, C.T., Sijian Li, 1988. Three-Dimensional Effective Elastic Constants for Thick Laminates. Journal of Composite Materials 22 (7), 629-639.

Sun, X.S., Chen, Y., Tan, V.B.C., Jaiman, R.K., Tay, T.E., 2013. Homogenization and Stress Analysis of Multilayered Composite Offshore Production Risers. Journal of Applied Mechanics 81 (3), 031003-031003.

Sun, X.S., Tan, V.B.C., Chen, Y., Tan, L.B., Jaiman, R.K., Tay, T.E., 2014. Stress analysis of multi-layered hollow anisotropic composite cylindrical structures using the homogenization method. Acta Mechanica 225 (6), 1649-1672.

Suresh, B.M., Sangeeta, B., Srikanth, G., Biswas, S., 2004. Composites for Offshore Applications. SEARCH 7 (9), 64-68.

Tafreshi, A., 2004. Delamination buckling and postbuckling in composite cylindrical shells under external pressure. Thin-Walled Structures 42 (10), 1379-1404.

Tamarelle, P.J.C., Sparks, C.P., 1987. High-performance composite tubes for offshore applications, Offshore technology conference, , Houston, TX.

Tan, L.B., Chen, Y., Jaiman, R.K., Sun, X., Tan, V.B.C., Tay, T.E., 2015. Coupled fluidstructure simulations for evaluating a performance of full-scale deepwater composite riser. Ocean Engineering 94, 19-35.

Tarn, J.-Q., Wang, Y.-M., 2001. Laminated composite tubes under extension, torsion, bending, shearing and pressuring: a state space approach. International Journal of Solids and Structures 38 (50-51), 9053-9075.

Tarnopol'skii, Y.M., Kulakov, V.L., Mungaiov, D.D., 1999. Composites in Offshore Technology in The Next Century. Mekhanika Kompozitnykh Matvrialov 35 (5), 549-560. 
Theotokoglou, E.E., 2006. Behaviour of thick composite tubes considering of delamination. Theoretical and Applied Fracture Mechanics 46 (3), 276-285.

Thomas, P., 2004. Composites manufacturing technologies: applications in automotive, petroleum, and civil infrastructure industries: economic study of a cluster of ATP-funded projects. NIST report, Delta Research Co., Chicago, IL.

Timoshenko, S.P., Gere, J.M., 1961. Theory of Elastic Stability. McGraw-Hill, New York.

Vedvik, N.P., Gustafson, C.-G., 2008. Analysis of thick walled composite pipes with metal liner subjected to simultaneous matrix cracking and plastic flow. Composites Science and Technology 68 (13), 2705-2716.

Vieira, I., Lima, B.L.P., Jacob, B., 2008. Optimization of Steel Catenary Risers for Offshore Oil Production Using Artificial Immune System, in: Bentley, P., Lee, D., Jung, S. (Eds.), Artificial Immune Systems. Springer Berlin Heidelberg, pp. 254-265.

Ward, E.G., Ochoa, O., Gilbert, R., 2007. A Comparative Risk Analysis of Composite and Steel Production Risers. Texas A\&M University.

Wiggenraad, J.F.M., Aoki, R., Gädke, M., Greenhalgh, E., Hachenberg, D., Wolf, K., Bübl, R., 1996. Damage propagation in composite structural elements - analysis and experiments on structures. Composite Structures 36 (3-4), 173-186.

Williams, J.G., 1994. Dimensional stability. Google Patents.

Williams, J.G., Sas-Jaworsky, A., 1999. Spoolable composite tubular member with energy conductors. Google Patents.

Xia, M., Takayanagi, H., Kemmochi, K., 2001. Analysis of multi-layered filament-wound composite pipes under internal pressure. Composite Structures 53 (4), 483-491.

Zhao, J.H., Chen, X., Dharani, L.R., Ji, F.S., 2000. Stress analysis of a multilayered composite cylinder with defects. Theoretical and Applied Fracture Mechanics 34 (2), 143-153. 


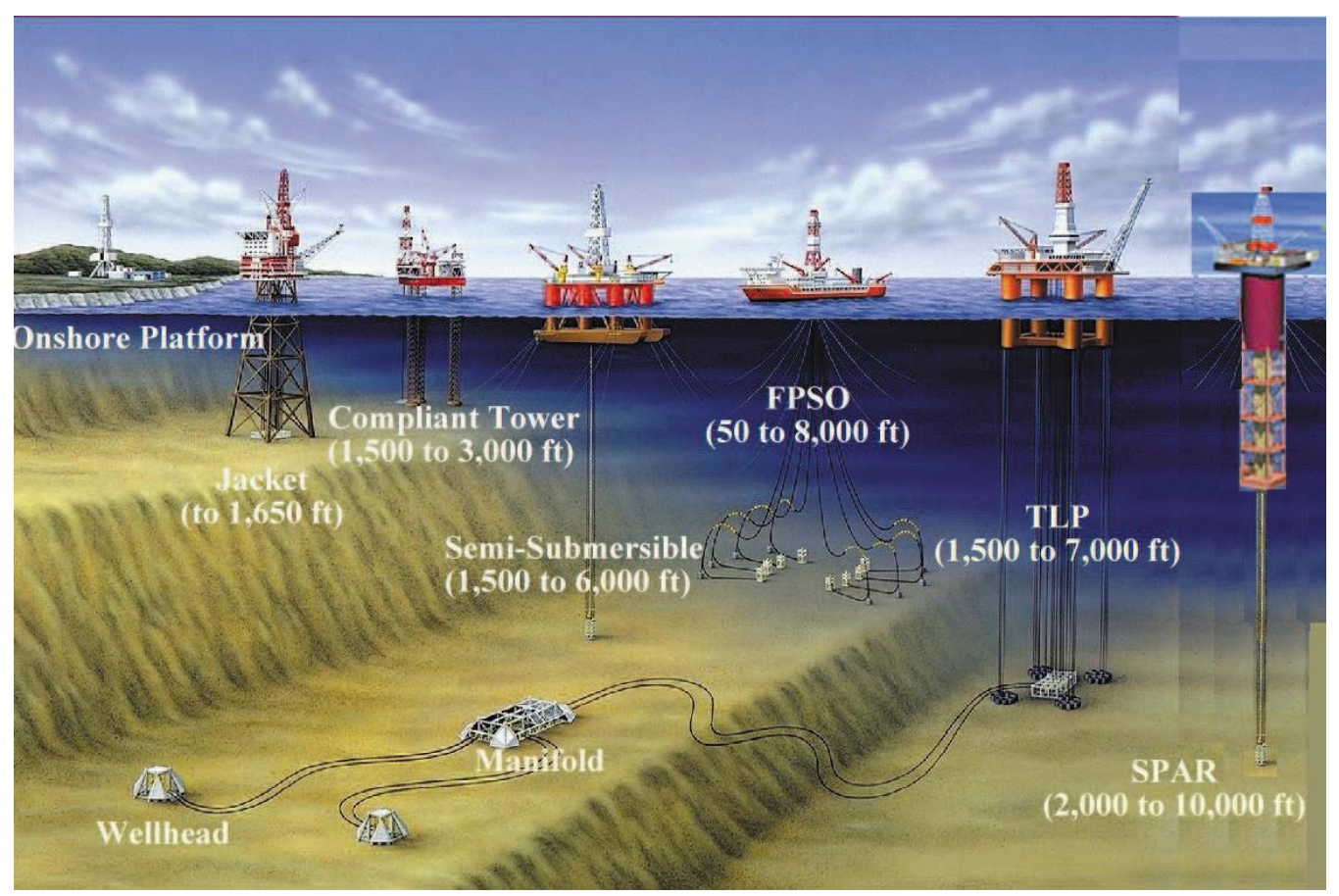

Fig. 1 Different types of Platforms and Risers, Huang (Huang, 2012)

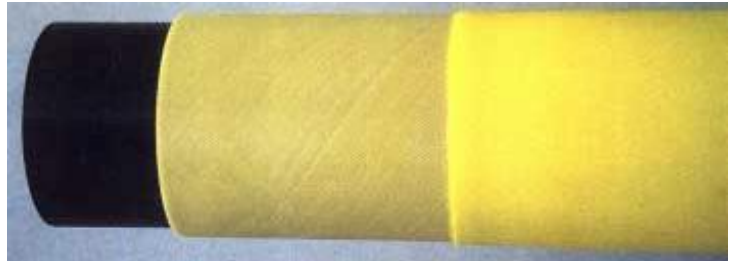

a. Bonded reinforced thermoplastic pipe

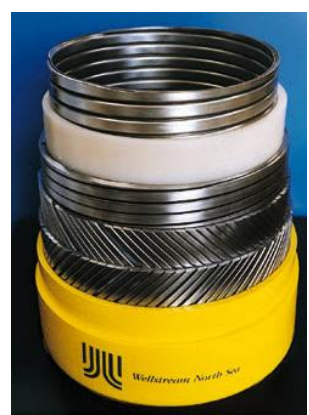

b. Unbonded flexible pipe

Fig. 2 Two typical types of composite risers: (a) Bonded reinforced thermoplastic pipe (Gibson, 2003) and (b) Unbonded flexible pipe (Oil \& Gas Journal, 1998) 

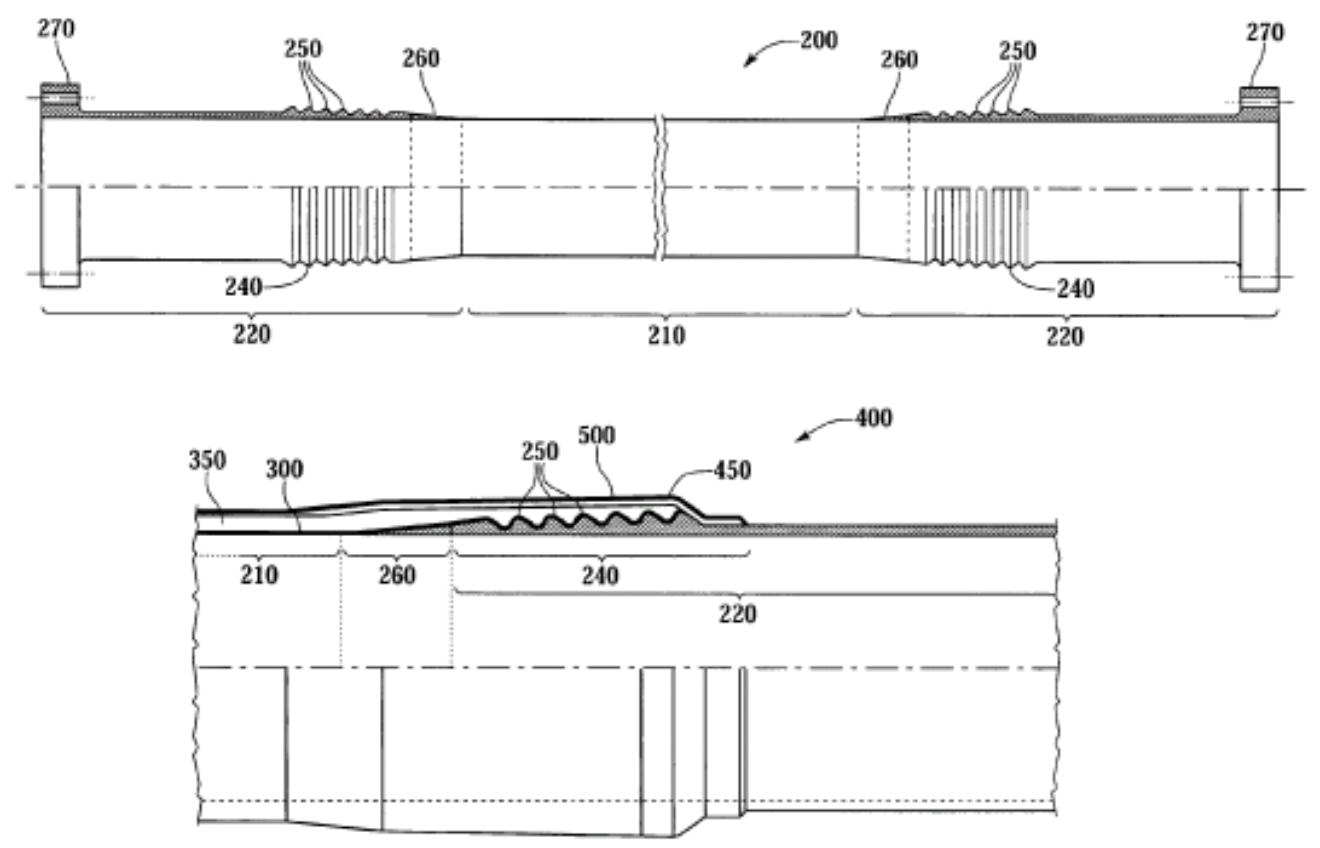

Fig. 3 A cross-sectional view of a composite riser assembly (Salama and Spencer, 2010) including metal liner assembly (200), liner assembly (210), connection assembly (220), the MCI (240), trap groove (250), transition ring (260), mechanical connectors (270), elastomeric shear ply (300), composite overwrap (350), composite riser section (400), external jacket (450), additional composite layer (500)

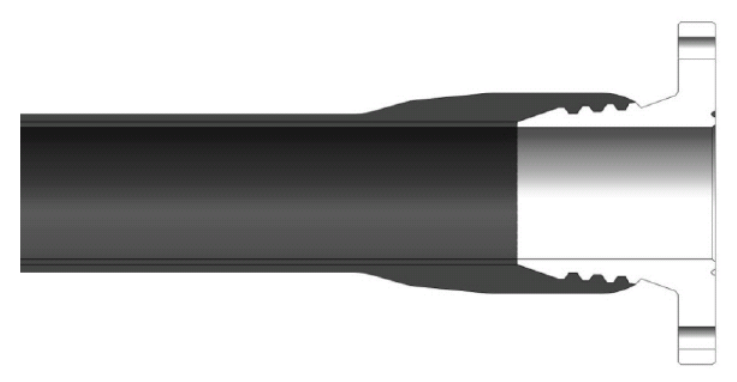

a.

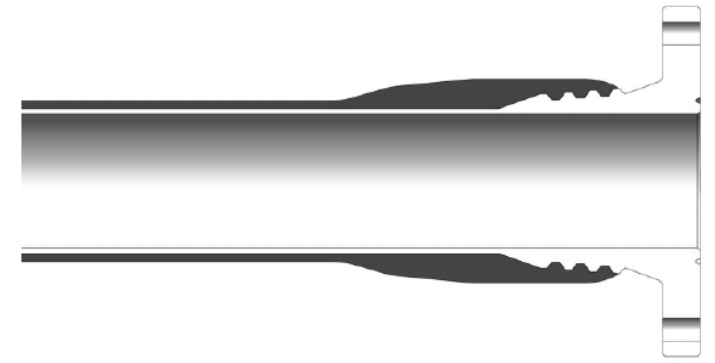

c.

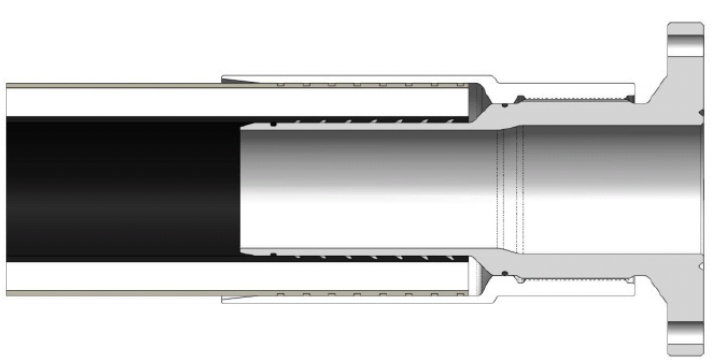

b.

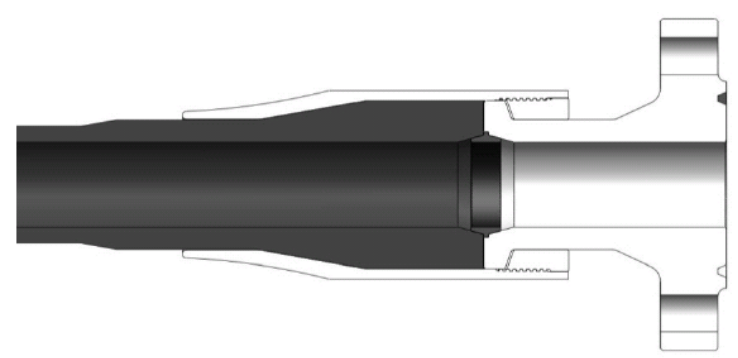

d.

Fig. 4 Different end fitting designs presented (Roberts and Hatton, 2013) including the trap-lock end fitting (a), swaged end fitting (b), metallic liner end fitting (c) and Magma end fitting (d) 


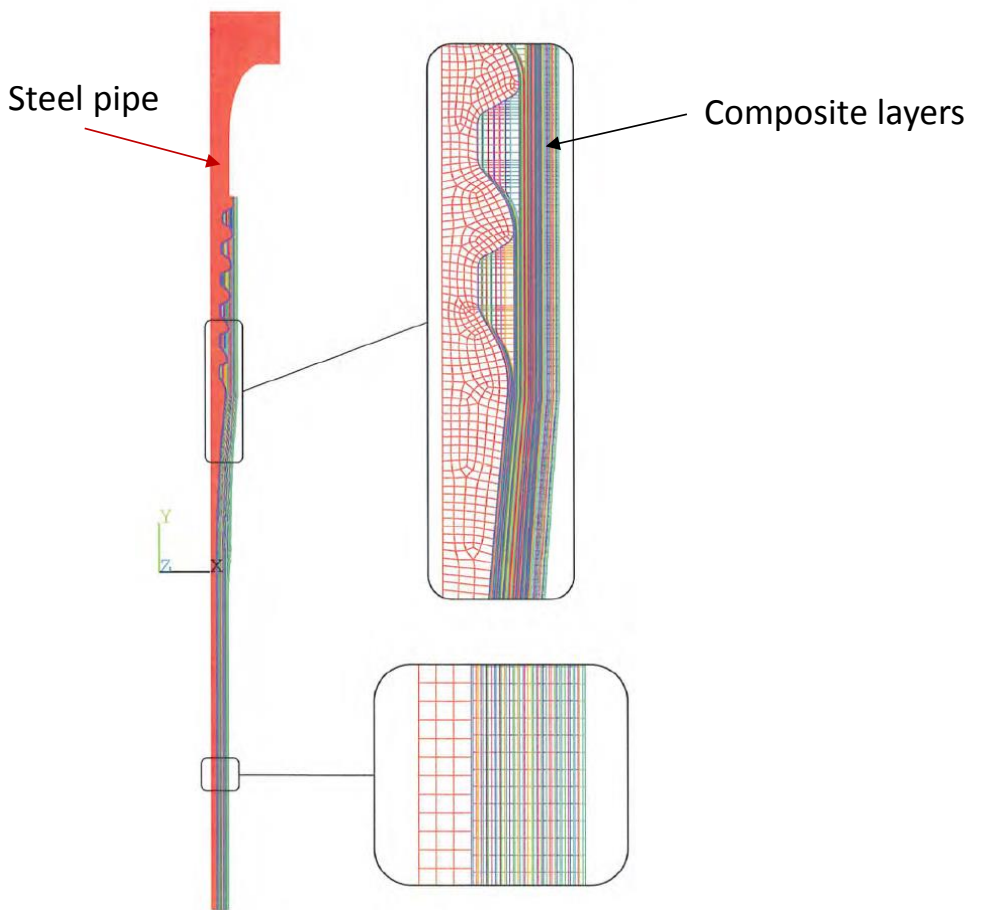

Fig. 5 FE local model of riser joint
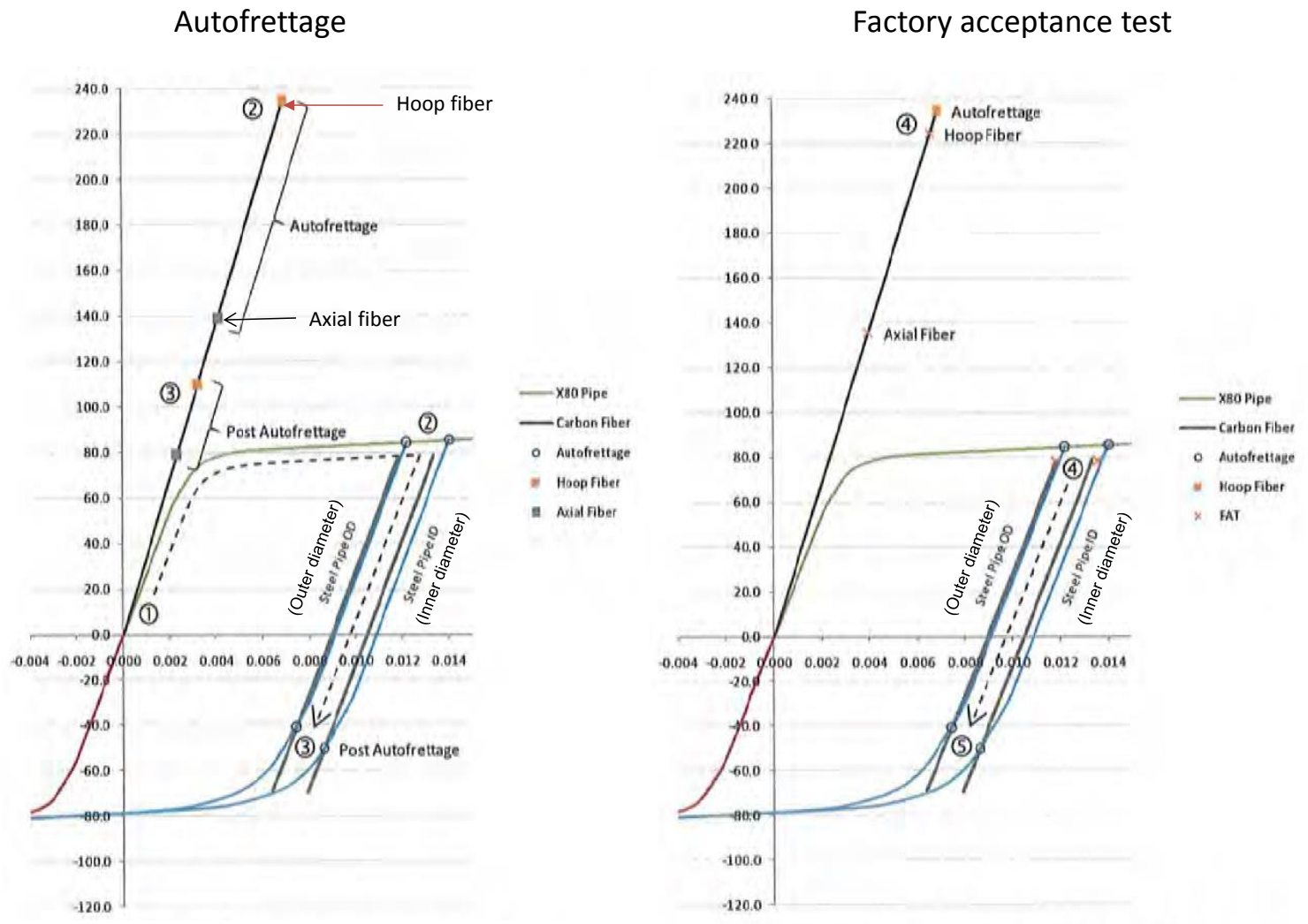

Fig. 6 Stress-strain responses of the steel and composite pipes for different tests 


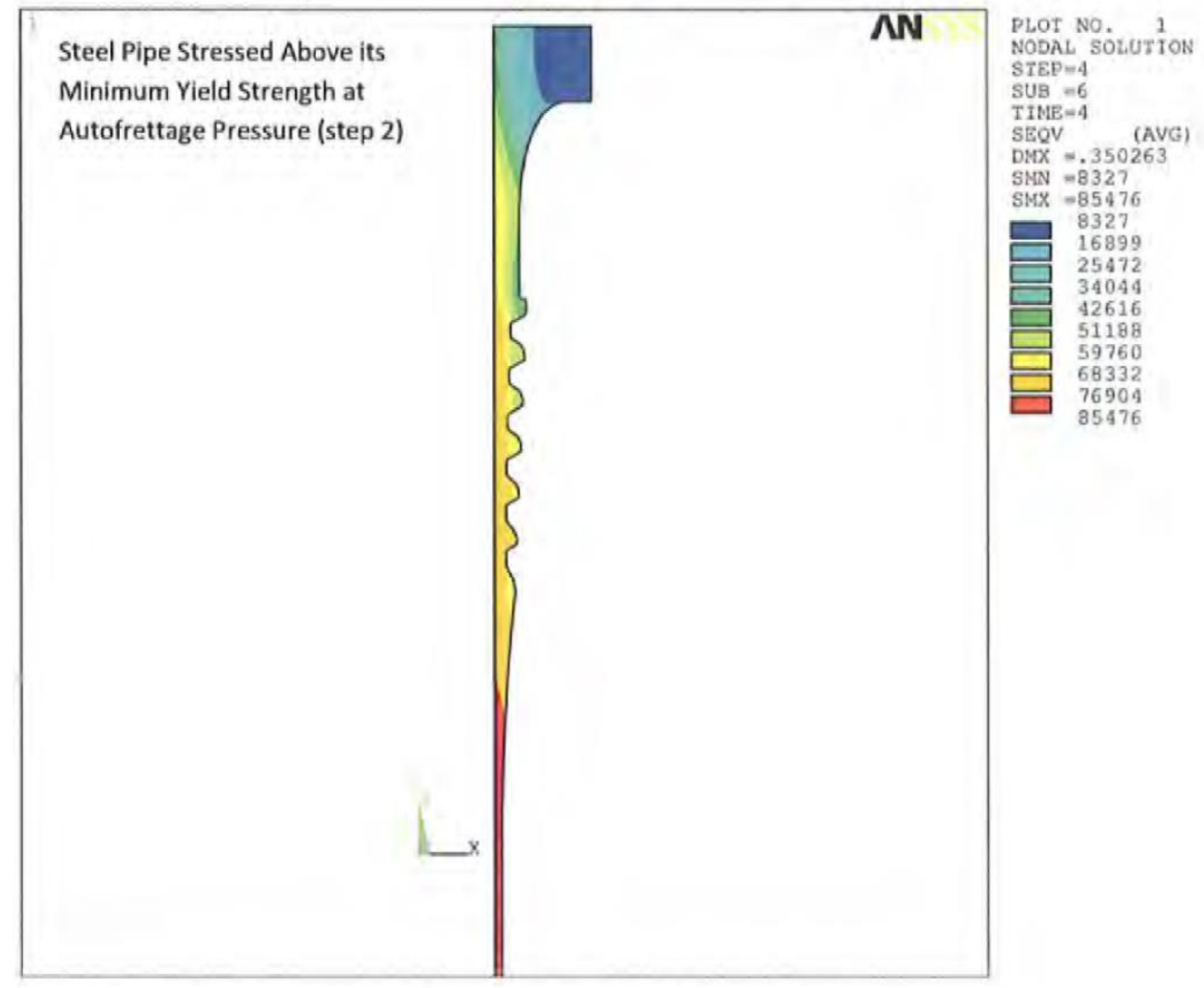

Fig. 7 Compression stress in the steel pipe 


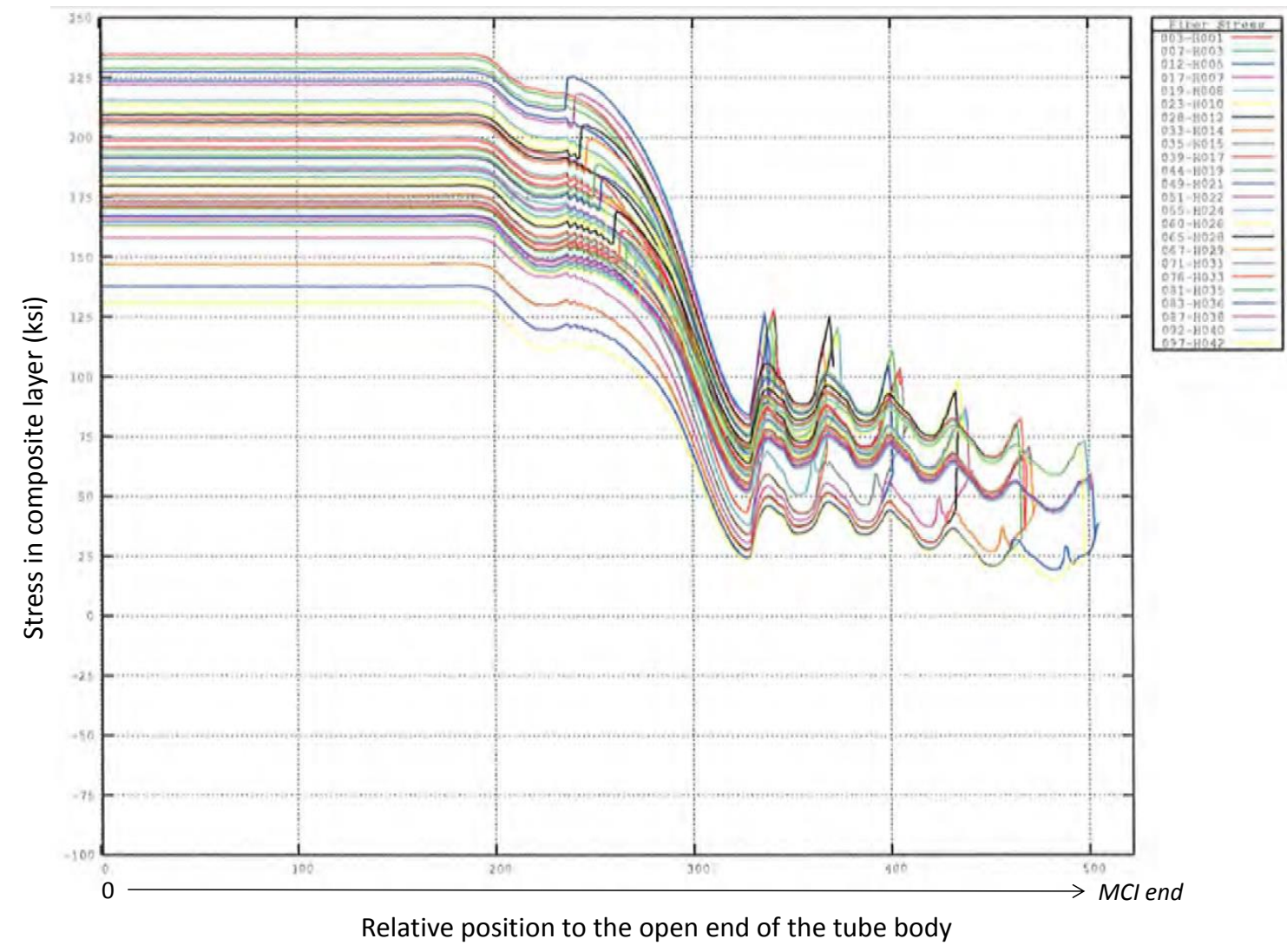

Fig. 8 Hoop stress in composite layers at relative position from the open plane

Table 1. Typical composite riser wall specification (Kim, 2007)

\begin{tabular}{|l|l|l|}
\hline \multirow{4}{*}{ Overall } & Inner diameter (in) & 9.72 \\
\cline { 2 - 3 } & Outer diameter (in) & 12.414 \\
\hline Internal Liner & Thickness (in) & 0.25 \\
\hline Structural Composite & Thickness & 0.972 \\
\cline { 2 - 3 } & Cross-Sectional Area $\left(\right.$ in $\left.^{2}\right)$ & 34.176 \\
\hline External Liner & Thickness (in) & 0.125 \\
\hline Carbon-Epoxy & Layer 1 $\left(88^{0}\right)$ thickness (in) & 0.081 \\
\cline { 2 - 3 } Composite Laminate & Layer 2 $\left(0^{0}\right)$ thickness (in) & 0.045 \\
\cline { 2 - 3 } & Layer 3 $\left(88^{0}\right)$ thickness (in) & 0.081 \\
\cline { 2 - 3 } & Layer 4 $\left(0^{0}\right)$ thickness (in) & 0.045 \\
\cline { 2 - 3 } & Layer 5 $\left(88^{0}\right)$ thickness (in) & 0.081 \\
\cline { 2 - 3 } & Layer 6 $\left(0^{0}\right)$ thickness (in) & 0.045 \\
\cline { 2 - 3 } & Layer 7 $\left(88^{0}\right)$ thickness (in) & 0.081 \\
\cline { 2 - 3 } & Layer 8 $\left(0^{0}\right)$ thickness (in) & 0.045 \\
\cline { 2 - 3 } & Layer 9 $\left(88^{0}\right)$ thickness (in) & 0.0405 \\
\cline { 2 - 3 } & Layer 10 $\left(0^{0}\right)$ thickness (in) & 0.045 \\
\cline { 2 - 3 } & Layer 11 $\left(88^{0}\right)$ thickness (in) & 0.0405 \\
\cline { 2 - 3 } & Layer 12 $\left(0^{0}\right)$ thickness (in) & 0.045 \\
\cline { 2 - 3 } & Layer 13 $\left(88^{0}\right)$ thickness (in) & 0.0405 \\
\hline
\end{tabular}




\begin{tabular}{|l|l|l|}
\hline \multirow{4}{*}{} & Layer 14 $\left(0^{0}\right)$ thickness (in) & 0.045 \\
\cline { 2 - 3 } & Layer 15 $\left(88^{0}\right)$ thickness (in) & 0.0405 \\
\cline { 2 - 3 } & Layer 16 $\left(0^{0}\right)$ thickness (in) & 0.045 \\
\cline { 2 - 3 } & Layer 17 $\left(88^{0}\right)$ thickness (in) & 0.0405 \\
\cline { 2 - 3 } & Layer 18 $\left(0^{0}\right)$ thickness (in) & 0.045 \\
\cline { 2 - 3 } & Layer 19 $\left(88^{0}\right)$ thickness (in) & 0.0405 \\
\hline
\end{tabular}

Table 2. Examples of Categorization of Loads, adapted from DNV (Det Norske Veritas, 2010b)

\begin{tabular}{|c|c|}
\hline Functional Loads & Accidental Loads \\
\hline $\begin{array}{l}\text { - Weight and buoyancy of riser, tubing, } \\
\text { coatings, marine growth, anodes, } \\
\text { buoyancy modules, contents and } \\
\text { attachments. } \\
\text { - Weight of internal fluid. } \\
\text { - Applied Tension for top-tension risers } \\
\text { - Installation induced residual loads or } \\
\text { pre-stressing. } \\
\text { - Pre-load of connectors. } \\
\text { - Applied displacements and guidance } \\
\text { loads, including active positioning of } \\
\text { support floater. } \\
\text { - Thermal loads. } \\
\text { - Soil pressure on buried risers. } \\
\text { - Differential Settlements. } \\
\text { - Loads from drilling operations. } \\
\text { - Construction loads and loads caused by } \\
\text { tools. }\end{array}$ & $\begin{array}{l}\text { - Fires and explosions } \\
\text { - Impact/collisions: } \\
\text { o riser collisions } \\
\text { ○ impact from dropped objects and } \\
\text { anchors } \\
\text { o impact from floater/floating objects } \\
\text { - Hook/snag loads: } \\
\text { o dragging anchor } \\
\text { - Failure of support systems: } \\
\text { o heave compensating system } \\
\text { malfunction (loss or stuck), } \\
\text { ○ loss of buoyancy, } \\
\text { ○ loss of mooring line or tendon } \\
\text { o dynamic positioning (DP) failure } \\
\text { o disconnect of Lower Marine Riser } \\
\text { package } \\
\text { - Exceedence of internal overpressure: } \\
\text { o loss of pressure safety system } \\
\text { o failure of well tubing or packers, } \\
\text { etc. } \\
\text { o pressure surge } \\
\text { o well kill - bullheading } \\
\text { - Environmental events: } \\
\text { o earthquake } \\
\text { o tsunamis } \\
\text { oiceberg }\end{array}$ \\
\hline Press & Environmental Loads \\
\hline $\begin{array}{l}\text { - External Hydrostatic pressure } \\
\text { - Internal fluid pressure: hydrostatic, } \\
\text { static and dynamic contributions } \\
\text { - Water Level }\end{array}$ & $\begin{array}{l}\text { - Waves } \\
\text { - Internal waves and other effects due to } \\
\text { difference in water density } \\
\text { - Current } \\
\text { - Earthquake } \\
\text { - Ice } \\
\text { - Floater motions induced by wind, } \\
\text { waves and current i.e.: } \\
\quad \text { M Mean offset including steady wave }\end{array}$ \\
\hline
\end{tabular}




\begin{tabular}{|l|l|}
\hline & $\begin{array}{l}\text { drift, wind and current forces } \\
\text { ○Wave frequency motions } \\
\text { ○Low frequency motions }\end{array}$ \\
\hline
\end{tabular}

Table 3. Key Design Load Cases, Hill et al. (Hill et al., 2006)

\begin{tabular}{|l|l|l|}
\hline & $\begin{array}{l}\text { Total Net } \\
\text { Buoyancy (tons) }\end{array}$ & $\begin{array}{l}\text { Maximum Riser } \\
\text { Tension (tons) }\end{array}$ \\
\hline $\begin{array}{l}\text { Buoyancy Close Distribution with maximum } \\
\text { Buoyancy Module of 3100 ft }\end{array}$ & 275 & 300 \\
\hline $\begin{array}{l}\text { Buoyancy Loose Distribution with maximum } \\
\text { Buoyancy Module of 7200 ft }\end{array}$ & 425 & 135 \\
\hline & Hoop Utilization & $\begin{array}{l}\text { Tensile } \\
\text { Utilization }\end{array}$ \\
\hline $\begin{array}{l}\text { Factory Acceptance test: } \\
\text { - No Tension } \\
\text { - Internal Pressure: } 1.5 \text { times of Design Pressure }\end{array}$ & 0.91 & 0.91 \\
\hline $\begin{array}{l}\text { Collapse of the internal carcass layer: } \\
\text { - Flooded pipe annulus } \\
\text { - Internal pressure = atmospheric }\end{array}$ & 0.85 & N/A \\
\hline $\begin{array}{l}\text { Extreme Operation: } \\
\text { - 100 year wave, 100 year current } \\
\text { - Design Pressure }\end{array}$ & 0.85 & 0.67 \\
\hline
\end{tabular}

Table 4. Summary of experimental programs on composite risers

\begin{tabular}{|c|c|c|}
\hline Test modes & Small-Scale riser testing & Large-Scale riser testing \\
\hline $\begin{array}{l}\text { Buckling/ } \\
\text { Collapse tests }\end{array}$ & & $\begin{array}{l}\text { Gibson (Gibson, 2003) } \\
\text { Ramirez and Engelhardt (Ramirez } \\
\text { and Engelhardt, 2009) }\end{array}$ \\
\hline Flexure/Tension & $\begin{array}{l}\text { Grant (Grant and Bradley, } \\
\text { 1995) } \\
\text { Ochoa (Ochoa and Ross, 1998) } \\
\text { Rodriguez and Ochoa } \\
\text { (Rodriguez and Ochoa, 2004) }\end{array}$ & $\begin{array}{l}\text { Sparks et al. (Sparks et al., 1998) } \\
\text { Gibson (Gibson, 2003) } \\
\text { Thomas (Thomas, 2004) }\end{array}$ \\
\hline \multicolumn{3}{|l|}{ Axisymmetric } \\
\hline Burst & Gibson (Gibson, 2003) & \\
\hline Fatigue tests & $\begin{array}{l}\text { Soden et al. (Soden et al., } \\
\text { 1993), } \\
\text { Ellyin et al. (Ellyin et al., 1997) } \\
\text { Ellyin and Martens (Ellyin and } \\
\text { Martens, 2001) } \\
\text { Mertiny et al. (Mertiny et al., }\end{array}$ & $\begin{array}{l}\text { Salama et al. (Salama et al., 1998) } \\
\text { Sparks et al. (Sparks et al., 1998) } \\
\text { Salama et al. (Salama et al., 2002) } \\
\text { Thomas (Thomas, 2004), } \\
\text { Cederberg(Cederberg, 2011) } \\
\text { Huybrechts (Huybrechts, 2002) }\end{array}$ \\
\hline
\end{tabular}




\begin{tabular}{|l|l|l|}
\hline & $\begin{array}{l}\text { 2004) } \\
\text { Chouchaoui and Ochoa } \\
\text { (Chouchaoui and Ochoa, 1999; } \\
\text { Chouchaoui et al., 1999) } \\
\text { Lindsey and Masudi (Lindsey } \\
\text { and Masudi, 1999) } \\
\begin{array}{l}\text { Gibson (Gibson, 2003) } \\
\text { Rodriguez and Ochoa } \\
\text { (Rodriguez and Ochoa, 2004); }\end{array}\end{array}$ & \\
\hline $\begin{array}{l}\text { Application } \\
\text { based }\end{array}$ & $\begin{array}{l}\text { Sobrinho et al. (Sobrinho et al., } \\
\text { 2010) }\end{array}$ & \\
\hline
\end{tabular}

Table 5. Summary of mechanics and numerical analysis methods for composite risers

\begin{tabular}{|c|c|c|c|}
\hline $\begin{array}{l}\text { Analysis } \\
\text { modes }\end{array}$ & Analytical approaches & 2D FEA & 3D FEA \\
\hline $\begin{array}{l}\text { Buckling/ } \\
\text { Collapse } \\
\text { analysis }\end{array}$ & $\begin{array}{l}\text { Brazier (Brazier, 1927) } \\
\text { Seide and Weingarten } \\
\text { (Seide and Weingarten, } \\
\text { 1961) } \\
\text { Reissner and Weinitschke } \\
\text { (Reissner and Weinitschke, } \\
\text { 1962) } \\
\text { Cheng and Ugural (Cheng } \\
\text { and Ugural, 1968) } \\
\text { Axelrad (Axelrad, 1965, } \\
\text { 1987) } \\
\text { Corona et al. (Corona and } \\
\text { Rodrigues, 1995) } \\
\text { Silva et al. (Silva et al., } \\
\text { 2013) }\end{array}$ & $\begin{array}{l}\text { Theotokoglou } \\
\text { (Theotokoglou, 2006) }\end{array}$ & \\
\hline Delamination & $\begin{array}{l}\text { Timoshenko and Gere } \\
\text { (Timoshenko and Gere, } \\
\text { 1961) } \\
\text { Kachanov (Kachanov, } \\
\text { 1988) } \\
\text { Wiggenraad et al. } \\
\text { (Wiggenraad et al., 1996) } \\
\text { Bai et al. (Bai et al., 1997) } \\
\text { Zhao et al. (Zhao et al., } \\
\text { 2000) } \\
\text { Rasheed and Tassoulas } \\
\text { (Rasheed and Tassoulas, }\end{array}$ & $\begin{array}{l}\text { Tafreshi (Tafreshi, } \\
\text { 2004) } \\
\text { Theotokoglou } \\
\text { (Theotokoglou, 2006) } \\
\text { Marinucci and de } \\
\text { Andrade (Marinucci } \\
\text { and de Andrade, 2006) }\end{array}$ & \\
\hline
\end{tabular}




\begin{tabular}{|c|c|c|c|}
\hline & $\begin{array}{l}\text { 2001) } \\
\text { Tafreshi (Tafreshi, 2004) } \\
\text { Marinucci and de Andrade } \\
\text { (Marinucci and de } \\
\text { Andrade, 2006) }\end{array}$ & & \\
\hline $\begin{array}{l}\text { Local failure } \\
\text { analysis }\end{array}$ & $\begin{array}{l}\text { Mendelson (Mendelson, } \\
\text { 1968) } \\
\text { Enie and Rizzo (Enie and } \\
\text { Rizzo, 1970) } \\
\text { Lekhnitskii (Lekhnitskii, } \\
\text { 1981) } \\
\text { Sun and Li (Sun and Sijian } \\
\text { Li, 1988) } \\
\text { Huang et al. (Huang et al., } \\
\text { 1993) } \\
\text { Huang and Hu (Huang and } \\
\text { Hu, 1994) } \\
\text { Xia et al. (Xia et al., 2001) } \\
\text { Tarn and Wang (Tarn and } \\
\text { Wang, 2001) } \\
\text { Silva et al. (Silva et al., } \\
\text { 2013) }\end{array}$ & $\begin{array}{l}\text { Andersen (Andersen, } \\
\text { 1996) } \\
\text { Rodriguez and Ochoa } \\
\text { (2004) } \\
\text { Ward et al. (Ward et al., } \\
\text { 2007) } \\
\text { Vedvik et al. (Vedvik } \\
\text { and Gustafson, 2008) }\end{array}$ & $\begin{array}{l}\text { Tarnopol'skii et } \\
\text { al.(Tarnopol'skii } \\
\text { et al., 1999) } \\
\text { Meniconi et al. } \\
\text { (2001) } \\
\text { Sun et al. (Sun } \\
\text { et al., 2013) } \\
\text { Chen et al. } \\
\text { (Chen et al., } \\
\text { 2013) } \\
\text { Kaboudian et al. } \\
\text { (Kaboudian et } \\
\text { al., 2014) } \\
\text { Sun et al. (Sun } \\
\text { et al., 2014) } \\
\text { Tan et al. (Tan } \\
\text { et al., 2015) }\end{array}$ \\
\hline $\begin{array}{l}\text { Global analysis } \\
\text { with } \\
\text { environmental } \\
\text { effects }\end{array}$ & $\begin{array}{l}\text { Ramos and Pesce (Ramos } \\
\text { and Pesce, 2004) } \\
\text { Vieira et al. (Vieira et al., } \\
\text { 2008) } \\
\text { Pina et al. (Pina et al., } \\
\text { 2011) }\end{array}$ & $\begin{array}{l}\text { Larson and Hanson } \\
\text { (Larsen and Hanson, } \\
\text { 1999) } \\
\text { Lima et al. (Leite Pires } \\
\text { de Lima et al., 2005) } \\
\text { Abouhamze and } \\
\text { Shakeri (Abouhamze } \\
\text { and Shakeri, 2007) } \\
\text { Chen et al. (Chen et al., } \\
\text { 2013) } \\
\text { Kaboudian et al.(Quest } \\
\text { Offshore, 2011) } \\
\text { Tan et al. (Tan et al., } \\
\text { 2015) }\end{array}$ & $\begin{array}{l}\text { Pham et al. } \\
\text { (Pham et al., } \\
\text { 2014) } \\
\text { Edmans et al. } \\
\text { (Edmans et al., } \\
\text { 2014) } \\
\text { Pham et al. } \\
\text { (Pham et al., } \\
\text { 2015) }\end{array}$ \\
\hline
\end{tabular}

